\title{
APS BEAMLINE STANDARD COMPONENTS HANDBOOK
}

\section{Version 1.1}

January 1992

Advanced Photon Source
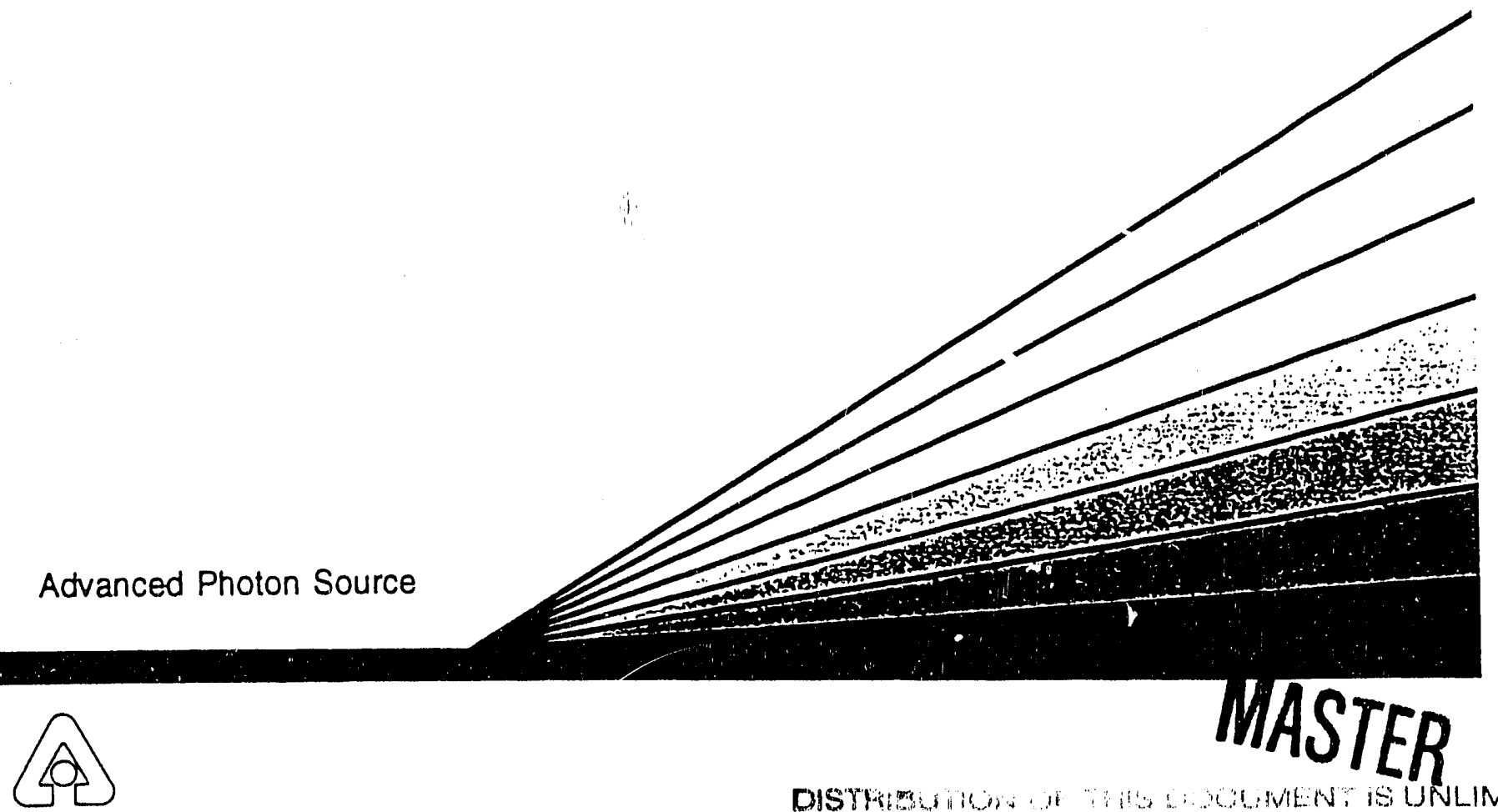
Argonne National Laboratory, with facilities in the states of Illinois and Idaho, is owned by the United States government, and operated by "The University of Chicago under the provisions of a contract with the Department of Energy.

\section{DISCLAIMER}

This report was prepared as an account of work sponsored by an agency of the United States Government. Neither the United States Government nor any agency thereof, nor any of their employees, makes any warranty, express or implied, or assumes any legal liability or responsibility for the accuracy, completeness, or usefulness of any information, apparatus, product, or process disclosed, or represents that its use would not infringe privately owned rights. Reference herein to any specific commercial product, process, or service by trade name, trademark, manufacturer, or other wise, does not necessarily constitute or imply its endorsement, recommendation, or favoring by the United States Government or any' agency thereof. The views and opinions of authors expressed herein do not necessarily state or reflect those of the United States Government or any agency thereof.

Reproduced from the best available copy.

Available to DOE and DOE contractors from the Office of Scientific and Technical Information P.O. Box 62

Oak Ridge, TN 37831

Prices available from (615) 576-8401, FTS 626-8401

Available to the public from the National Technical Information Service

U.S. Department of Commerce 5285 Port Royal Road Springfield, VA 22161 
Distribution Category: Atomic, Molecular, and Chemical Physics (UC-411)

\section{ARGONNE NATIONAL LABORATORY \\ 9700 South Cass Avenue \\ Argonne, Ilinois 60439}

ANL/APS/LS-187

\section{APS BEAMLINE STANDARD COMPONENTS HANDBOOK}

\section{Version 1.1}

Tuncer M. Kuzay

Experimental Facilities Division

January 1992

work sponsored by

U.S. DEPARTMENT OF ENERGY

Office of Energy Rese'trch 


\section{CONTENTS}

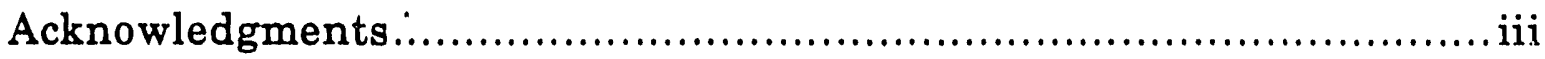

Introduction ..................................................................... 1

Descriptions, Specifications, and Drawings of the

APS Standard Components......................................................4

1. Filter Assembly....................................................... 5

2. ID White Beam Slits......................................................... 7

3. BM White Beam Slits ..................................................... 9

4. Monochromatic Beam Slits............................................... 11

5. White Beam Photon Shutters ....................................... 13

6. Safety Shutters ........................................................... 14

7. Light Load Stepping Linear Actuators ................................ 16

8. Heavy Load Stepping Linear Actuators ................................. 18

9. Light Load Pneumatic Linear Actuators ................................20

10. Heavy Load Pneumatic Linear Actuators...............................22

11. Beam Transport Vacuum Specifications............................ 24

12. Kinematic Mount Support Tables and

Kinematic Mount Stages............................................. 25

13. FOE and Experimental Station Hutches...............................34

14. Shielded Monochromatic Transport rid Pump Station.............. 37

15. Stepping Motor Drivers/Controiiers.................................... 43

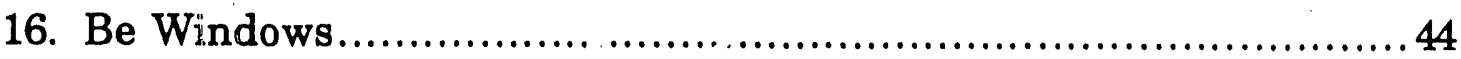

17. Monochromatic Beam Position Monitors/Supports.................. 45

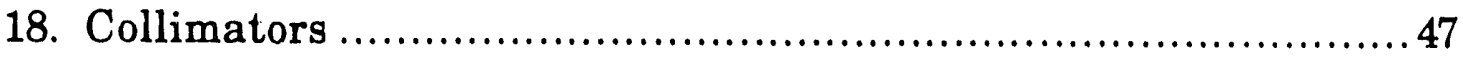

19. Transport and Hutch Shielding Specifications....................... 48

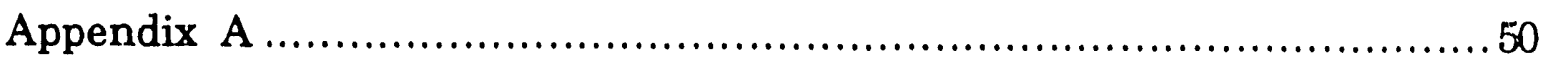




\section{ACKNOWLEDGMENTS}

I would like to thank the Insertion Device, Beamlines, and Engineering and Construction Groups of the Experimental Facilities Division for their work on the design of the APS beamline "standard components." I would like to acknowledge the significant input to this document from the following individuals: Deming Shu, Juan Barraza, Thomas Sanchez, Joseph Chang, Ercan Alp, Steve Davey, Susan Picologlou, Howard Czerwinski, and Mike Muscia. I thank the members of the Beamline Standardization and Modularization Committee for the time and effort they have contributed to the process of identifying and specifying the standard components. In addition, I would like to thank various users and CAT representatives who have contributed ideas and suggestions toward this effort. 


\section{INTRODUCTION}

It is clear that most Advanced Photon Source (APS) Collaborative Access Team (CAT) members would like to concentrate on designing specialized equipment related to their scientific programs rather than on routine or standard beamline components. Thus, an effort is in progress at the APS to identify standard and modular components of APS beamlines. Identifying standard components is a nontrivial task because these compionents should support diverse beamline objectives. To assist with this effort, the APS has obtained advice and help from a Beamline Standardization and Modularization Committee consisting of the following experts in beamline design, construction, and operation:

\author{
Richard Buyce \\ Richard Hewitt \\ Tunch M. Kuzay \\ Richard Levesque \\ Ed Melczer \\ Dennis M. Mills \\ Tom Oversluizen \\ Wilfried Schildkamp
}

SSRL EXXON and CMC CAT

APS

LLNL

LBL/ALS

APS and NOX CAT

NSLS

University of Chicago and CARS CAT

A group of CAT representatives (Haydn Chen, Kevin D'Amico, Pedro Montano, and Brian Stephenson) joined in a recent meeting of the committee to lend their views on the subject.

Based on the charge given to this committee by Gopal Shenoy, Director of the Experimental Facilities of the Advanced Photon Source on Jan. 22, 1990 (see Appendix A), the committee identified the following tasks:

1) to identify standard and modular components of an APS insertion device beamline,

2) to insure safety and quality in the beamline design concepts,

3) to develop conceptual and engineering designs for the components,

4) to review the designs,

5) to develop prototypes.

6) to disseminate the information to the user community and vendors.

(Tasks 2, 5, and 6 are carried out exclusively by the staff of the APS.) 
In addition, the guidelines given to this committee called for the following considerations:

- modular design of as many components as possible,

- vendor production design to reduce cost to users,

- safety of users, staff, and equipment,

- ALARA* design objective,

- Experiment Hall should be a Class IV restricted area (0.05 to $5 \mathrm{mrem} / \mathrm{h}$ ),

- sandwiched shielded transport design to prevent inadvertent removal of required shielding,

- interlocks with adequate visual and audible alarms to prevent human errors.

- provide spares for standard components by keeping them in the APS stockruom.

With these guidelines in mind, the staff of the Experimental Facilities Division identified various components thought to be standard items for beamlines, regardless of the specific scientific objective of a particular beamline. A generic beamline layout (see nest page) formed the basis for this identification. This layout is based on a double-crystal (or multi-layer) monochromator as the first optical element, with the possibility of other elements to follow. Pre-engineering designs were then made of the identified standard components. The Beamline Standardization and Modularization Committee has reviewed these designs and provided very useful input regarding the specifications of these components. We realize that there will be other configuracions (white beamlines, dispersive energy beamlines, etc.) that may require special or modified components. (For example, the first optics enclosure [FOE] can also be used for white radiation work by removal of the monochromatizing optics.)

This Handbook in its current version (1.1) contains descriptions, specifications, and pre-engineering design drawings of these standard components. In the future, the APS plans to add engineering drawings of identified standard beamline components. Future versions of this Handbook will become available to both the CATs and potential vendors. Use of standard components should result in major cost reductions for CATs in the areas of beamline design and construction.

Because of the involved nature of the job at hand, we encourage CAT Directors to inform us of their specific needs as they progress in completing their beamline conceptual designs.

\footnotetext{
" ALARA ("as low as reasonably achievable") refers to DOE's policy of minimizing radiation exposure to personnel and equipment.
} 


\section{ADVANCED PHOTON SOURCE}

APS GENERIC BEAMLINE SCHEMA

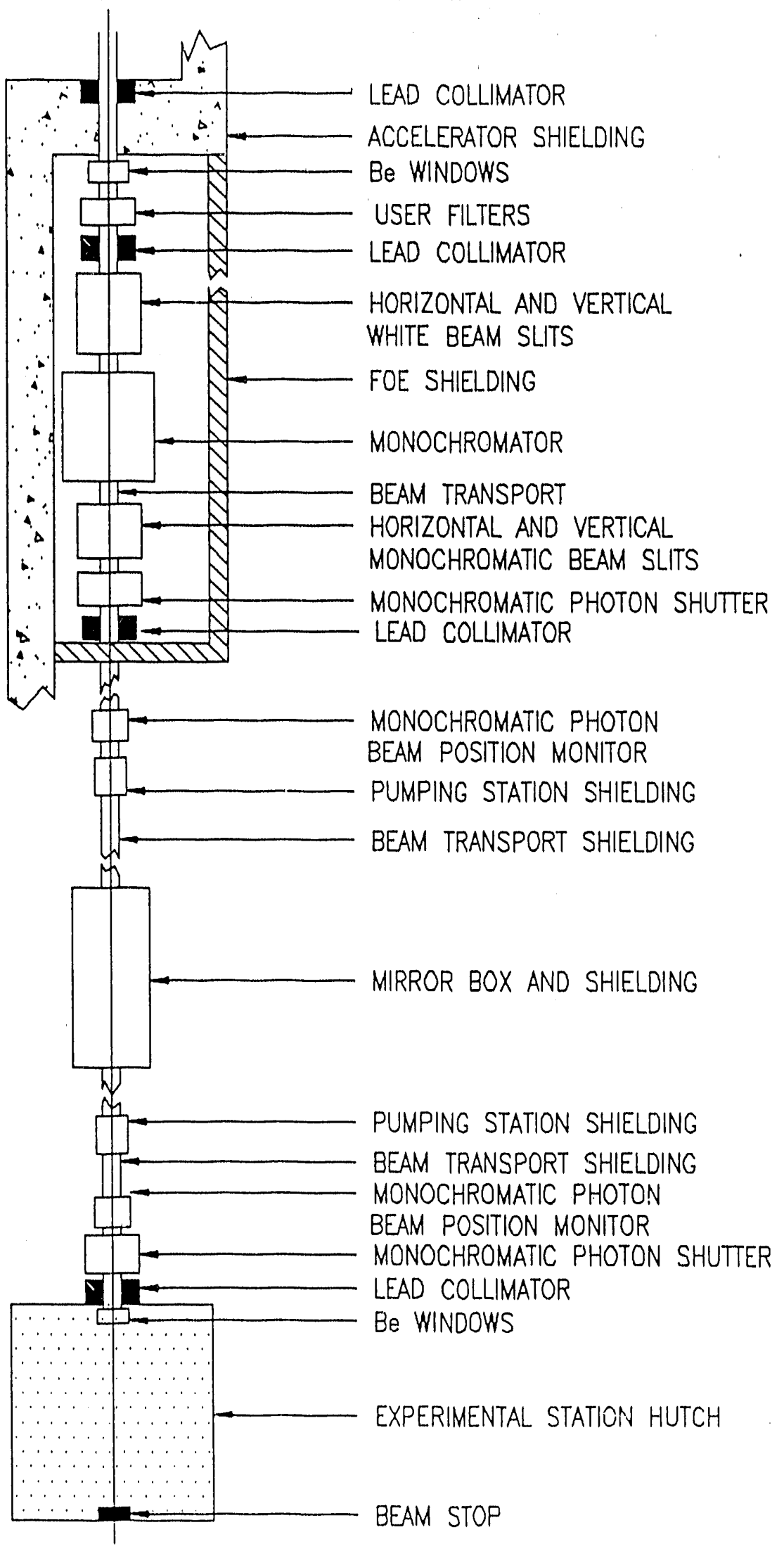

Generic Beamline Layout 
DESCRIPTIONS, SPECIFICATIONS, AND DRAWINGS OF THE

APS STANDARD COMPONENTS 


\section{APS Filter Assembly}

- Remote selection of $\mathrm{x}$-ray filters

- White beam compatible

- Multiple filter assemblies provide selectable filter combinations

- Standard filter wheel mounts

- Motor-driven filter wheels

- Beamline filters for attenuation and spectral selection

The APS Filter Assembly is designed to provide a modular beamline filtering system. The assembly can be mounted on the user's beamline on the experiment floor. For ease of replacement, the in-vacuum foil filters are mounted on standardized disks. The filters are radiatively cooled to a water-cooled base. The filter assemblies are Conflat mountable and can be mounted in tandem on a beamline. Current designs are for a module with four filter wheels, each of which can contain four filters. An offset wheel design that can contain a larger number of filters is also being considered. 


\section{USER FILTER ASSEMBLY}

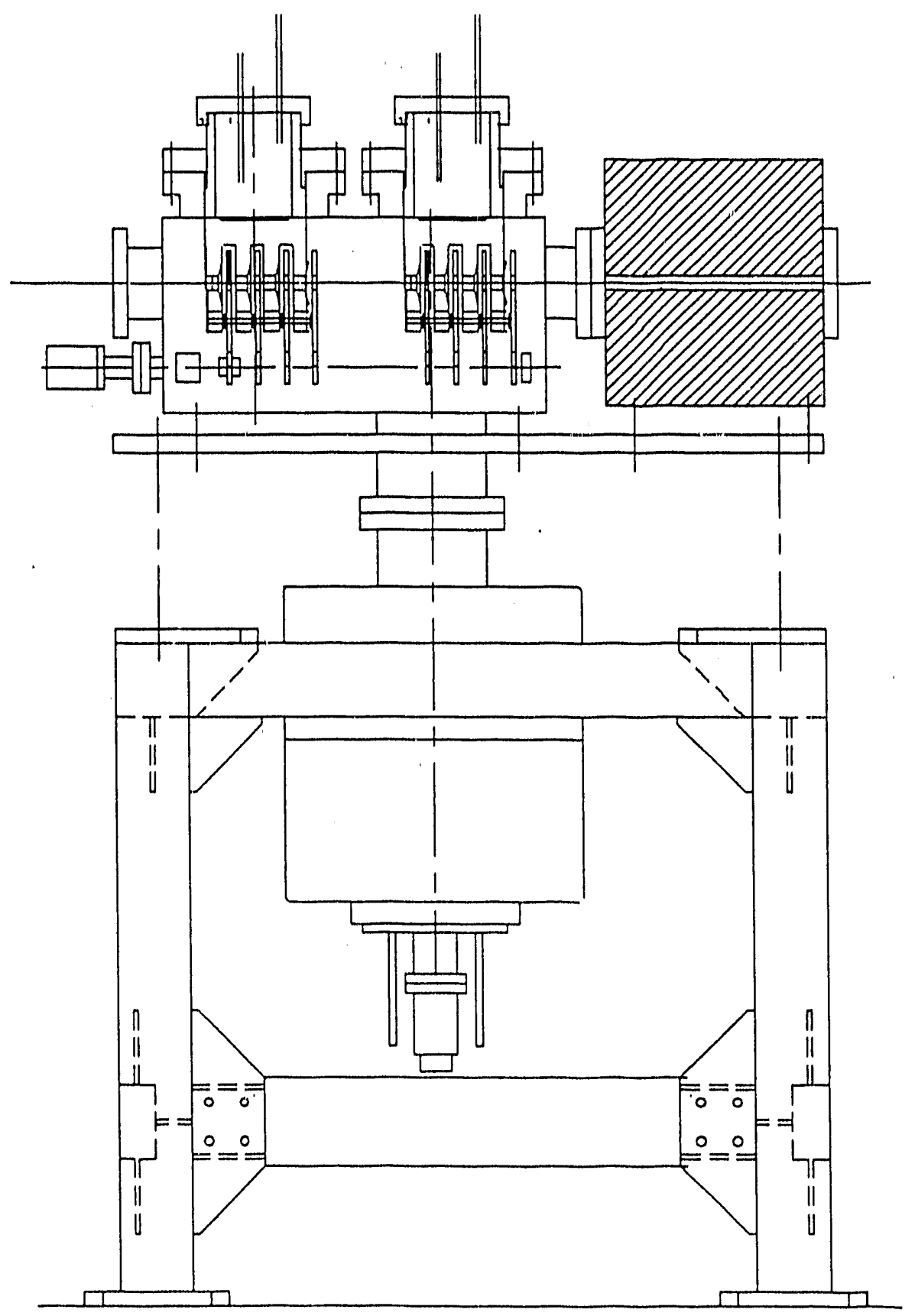

FL.DWG $01 \cdots 20-92$

Figure 1-1 


\section{APS ID White Beam Slits}

- Horizontal and vertical slits

- White beam compatible

- Four independent precision high load actuators

- Cooling for structural, vibrational, and thermal stability

- UHV compatible

- Provide for closed aperture

The APS white beam slits provide for precise aperture for the white synchrotron radiation. APS standard high load stepping linear actuator modules are used with horizontal and vertical slits. Each of the four masks in the slit assembly is independently movable. The beam intercepts the slits with a grazing incidence. Water-cooled copper foam removes the heat from the slit masks. The masks have been designed so that a pair of slits can be removed through a single vacuum port.

Specifications:

- Slit positional resolution:

$10 \mu \mathrm{m}$

- Slit positional reproducibility:

$25 \mu \mathrm{m}$

- Vertical aperture:

$0-30 \mathrm{~mm}$

- Horizontal aperture:

$0-100 \mathrm{~mm}$

- Grazing incidence angle:

$3^{\circ}$ (typical)

- Vacuum tank flanges:

6 inch

- Vacuum tank length:

$<1500 \mathrm{~mm}$

- Actuator:

Standard APS heavy load stepping linear actuator

- Actuator drive:

Stepping motor with shaft encoder

- Actuator maximum speed:

$20 \mathrm{~mm} / \mathrm{min}$ 
APS ID WHITE BEAM HORIZONTAL AND VERTICAL SLITS
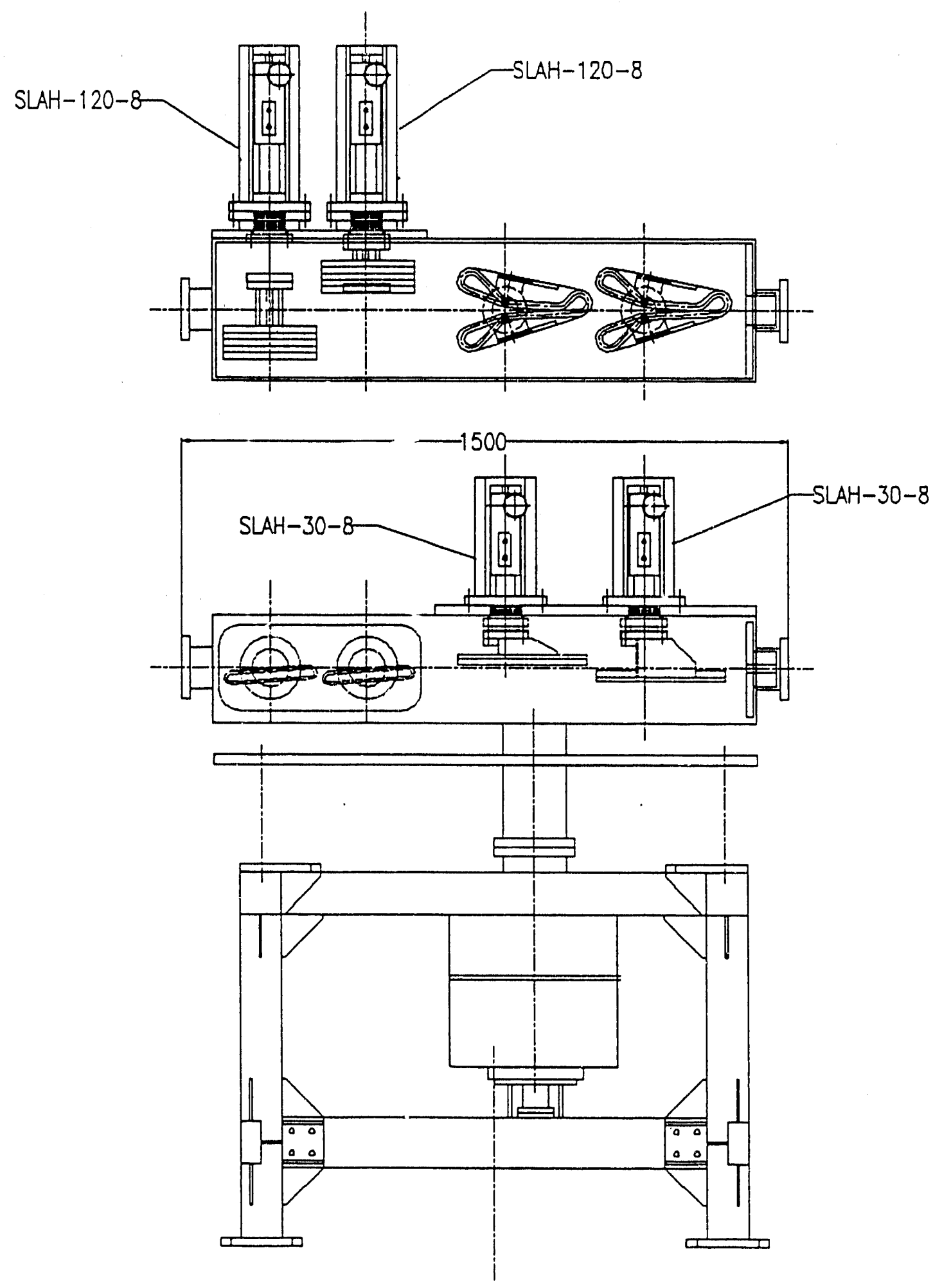

ivsowe $01-18-92$

Figure 2-1 


\section{APS BM White Beam Slits}

- Horizontal and vertical slits

- White beam compatible

- Four independent precision light load actuators

- Cooling for structural, vibrational, and thermal stability

- UHV compatible

- Provide for closed aperture

The APS white beam slits provide for precise aperture for the white synchrotron radiation. APS standard light load stepping linear actuator modules are used with horizontal and vertical slits. Each of the four masks in the slit assembly is independently movable. The beam intercepts the slits with a normal incidence. Water cooling removes the heat from the slit masks. The masks have been designed so that each one can be removed through a single vacuum port.

Specifications:

- Slit positional resolution:

$10 \mu \mathrm{m}$

- Slit positional reproducibility:

$25 \mu \mathrm{m}$

- Vertical aperture:

$0-30 \mathrm{~mm}$

- Horizontal aperture:

$0-120 \mathrm{~mm}$

- Vacuum tank flanges:

8 inch

- Vacuum tank length:

$<900 \mathrm{~mm}$

- Actuator:

Standard APS light load stepping linear actuator

- Actuator drive:

Stepping motor with shaft encoder

- Actuator maximum speed:

$50 \mathrm{~mm} / \mathrm{min}$ 


\section{ADVANCED PHOTON SOURCE}

BM WHITE BEAM HORIZONTAL AND VERTICAL SLITS

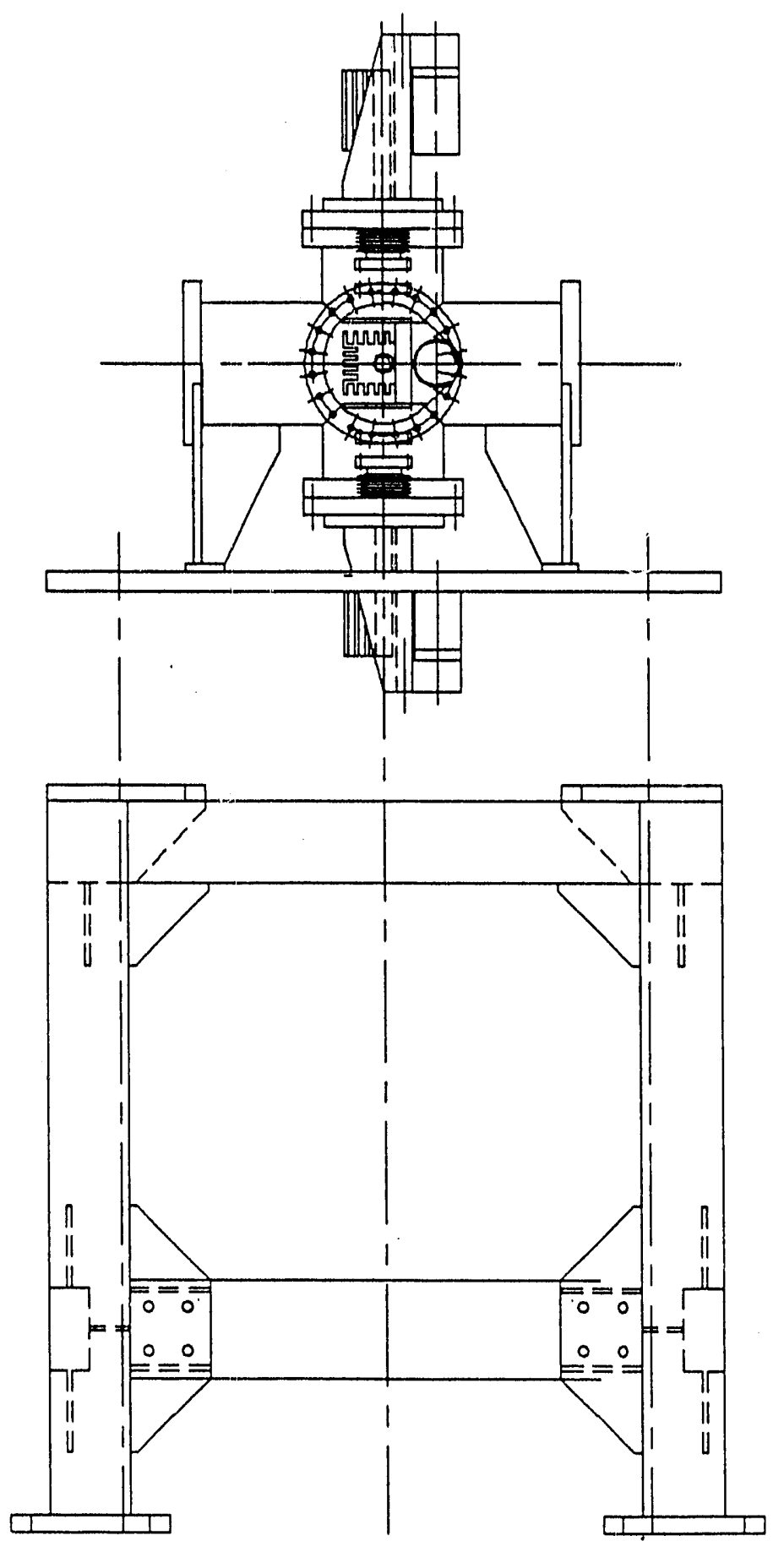

BMWS.DWG $01-20-92$

Figure 3-1 


\section{APS Monochromatic Beam Slits}

- Horizontal and vertical slits

- Monochromatic beam compatible

- ID and BM monochromatic beamline slits

- Four independent precision light load actuators

- Convective air cooling.

- UHV compatible

- Provide for closed aperture

The APS monochromatic beam slits provide for precise aperture for the monochromatic synchrotron radiation. APS standard light load actuator modules are used with horizontal and vertical slits. Each of the four masks in the slit assembly is independently movable. The beam intercepts the slits with normal incidence. Convective air cooling removes the heat from the slit masks. The slits have been designed to be mounted on a standard 6-way cross.

Specifications:

- Slit positional resolution: $\quad 1 \mu \mathrm{m}$

- Slit positional reproducibility: $\quad 5-10 \mu \mathrm{m}$

ID slits: Vertical aperture: $\quad 0-30 \mathrm{~mm}$

Horizontal aperture: $\quad 0-120 \mathrm{~mm}$

Vacuum tank flanges: 8 inch

BM slits: Vertical aperture: $\quad 0-30 \mathrm{~mm}$

Horizontal aperture: $\quad 0-120 \mathrm{~mm}$

Vacuum tank flangis: $\quad 8$ inch

- Actuators:

Standard APS light load stepping linear actuator

- Actuator Maximum speed: $\quad 20 \mathrm{~mm} / \mathrm{min}$ 


\section{ADVANCED PHOTON SOURCE}

ID MONOCHROMATIC BEAM HORIZONTAL AND VERTICAL SLITS

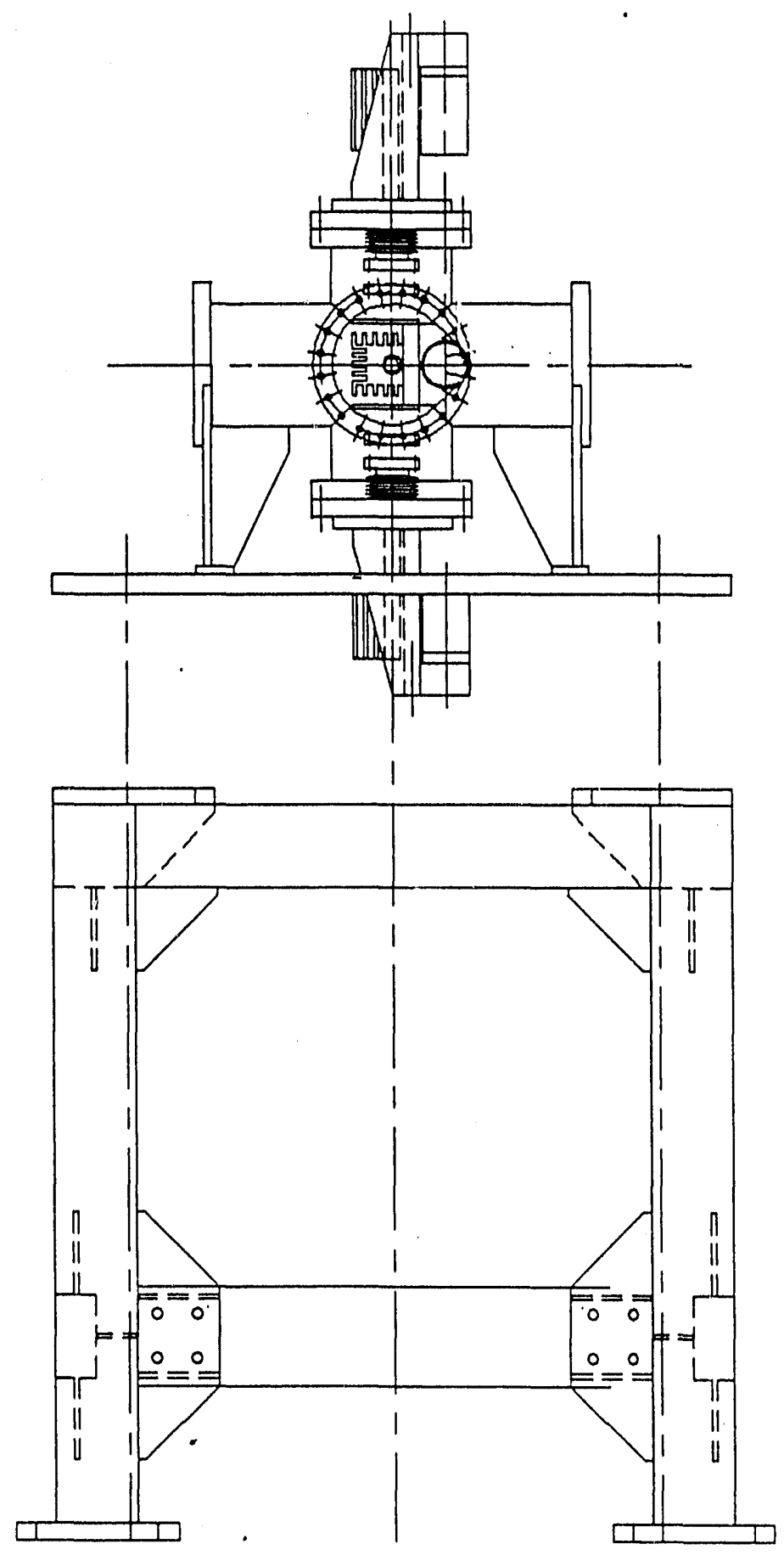

IDMONOS.DWG 01-20-92

Figure 4-1 


\section{APS White Beam Photon Shutters}

(design not yet included in Handbook, version 1.1)

- Stops white synchrotron radiation

The design will be the same as that of the front-end photon shutter. 


\section{APS Safety Shutters}

\section{(specifications not yet included in Handbook, version 1.1)}

- Stops Bremsstrahlung radiation

The design will be the same as that of the front-end safety shutter. 

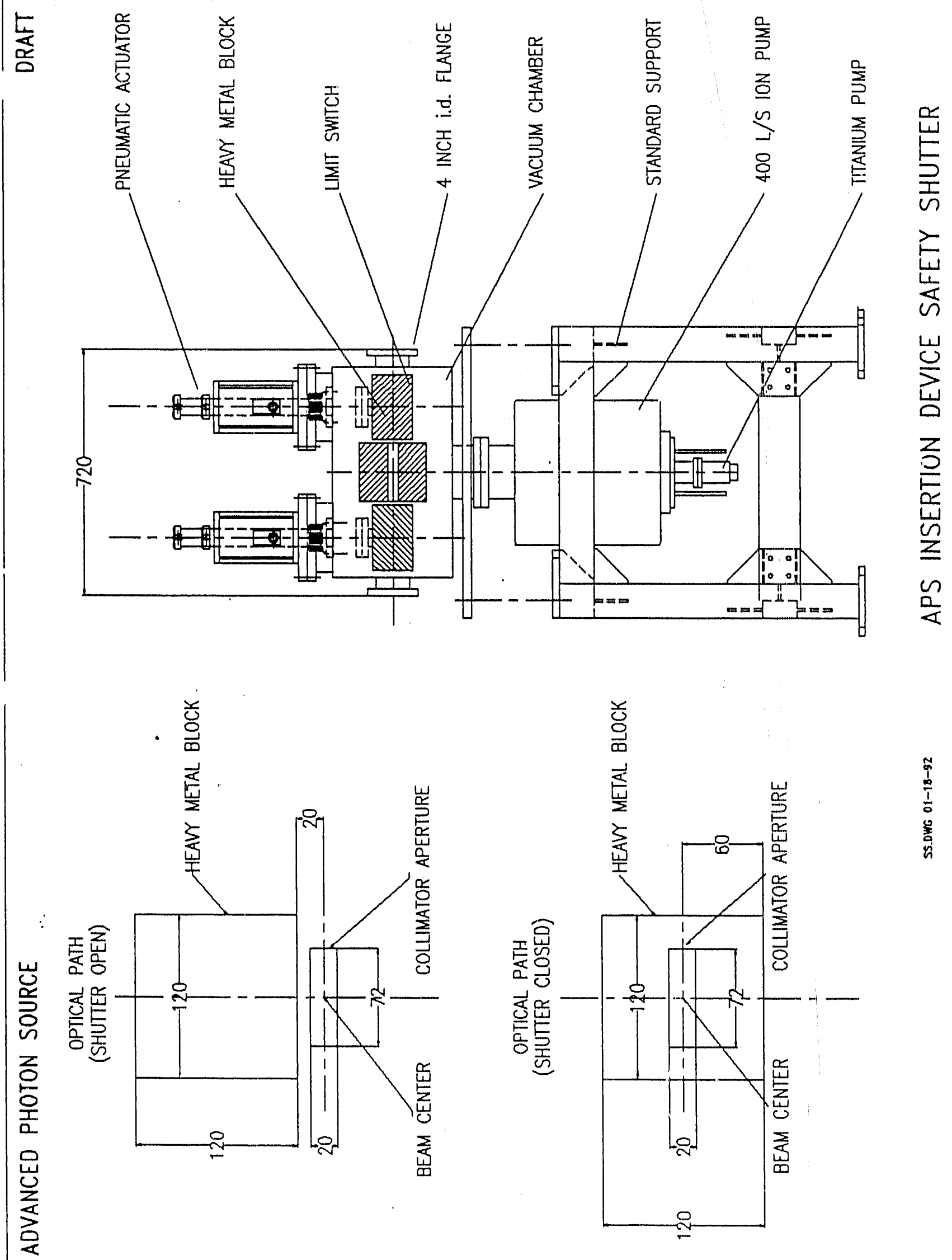

ć 


\section{APS Light Load Stepping Liraear Actuators}

SLAL-30-8, SLAL-75-8, SLAL-120-8

- Light load actuators

- For use with APS ID and BM monochromatic slits and BM white slits

- Stepping-motor driven with shaft encoder

A typical application for these actuators is to drive the APS monochromatic beam slits and BM white beam slits. There are three different ranges of travel designed.

Specifications:

- Slide type:

Linear rolling

- Travel ranges:

30,75 , and $120 \mathrm{~mm}$

- Motion resolution:

$1 \mu \mathrm{m}$

- Motion reproducibility:

$5 \mu \mathrm{m}$

- Straightness:

$2 \times 10^{-4} \mathrm{rad} / 25 \mathrm{~mm}$

- Total axial load:

$40 \mathrm{~kg}$

- Vacuum load:

$19 \mathrm{~kg}$

- Minimum useful axial load:

$10 \mathrm{~kg}$

Stepping motor:

Slo-Syn M063-LE06-E

- Actuator flange O. D.:

8 inch

- Feedthrough flange O. D.:

2.75 inch

- Maximum feedthrough diameter:

$25 \mathrm{~mm}$

- Redundant limit switches

-Encoder:

Optical on motor shaft

-Maximum speed:

$50 \mathrm{~mm} / \mathrm{min}$

-Vacuum:

UHV compatible 
ADVANCED PHOTON SOURCE

DRAFT APS LIGHT LOAD STEPPING LINEAR ACTUATOR
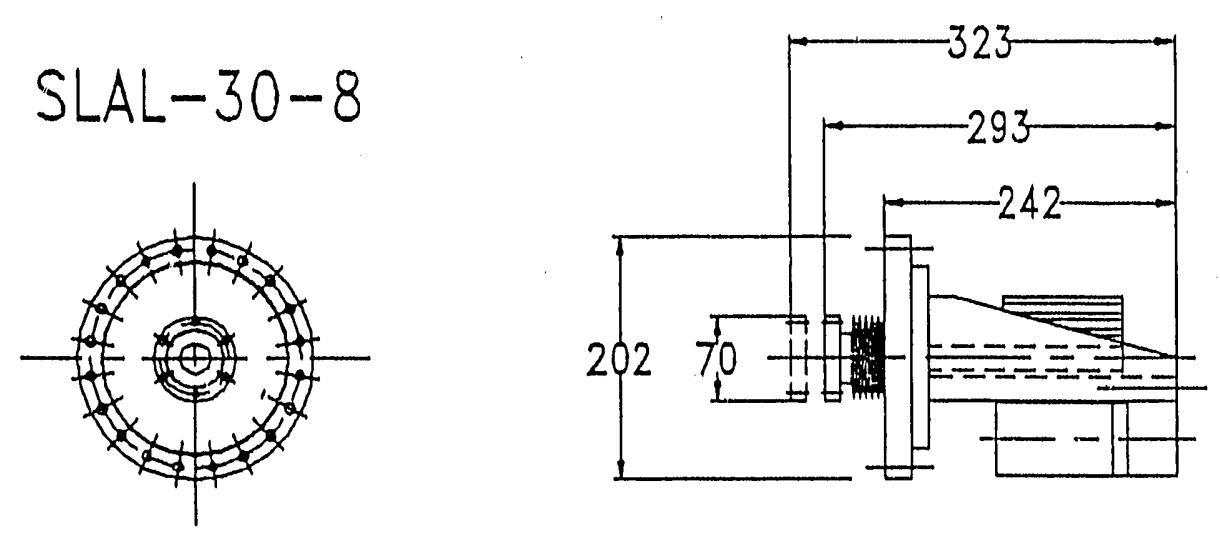

SLAL-75-8
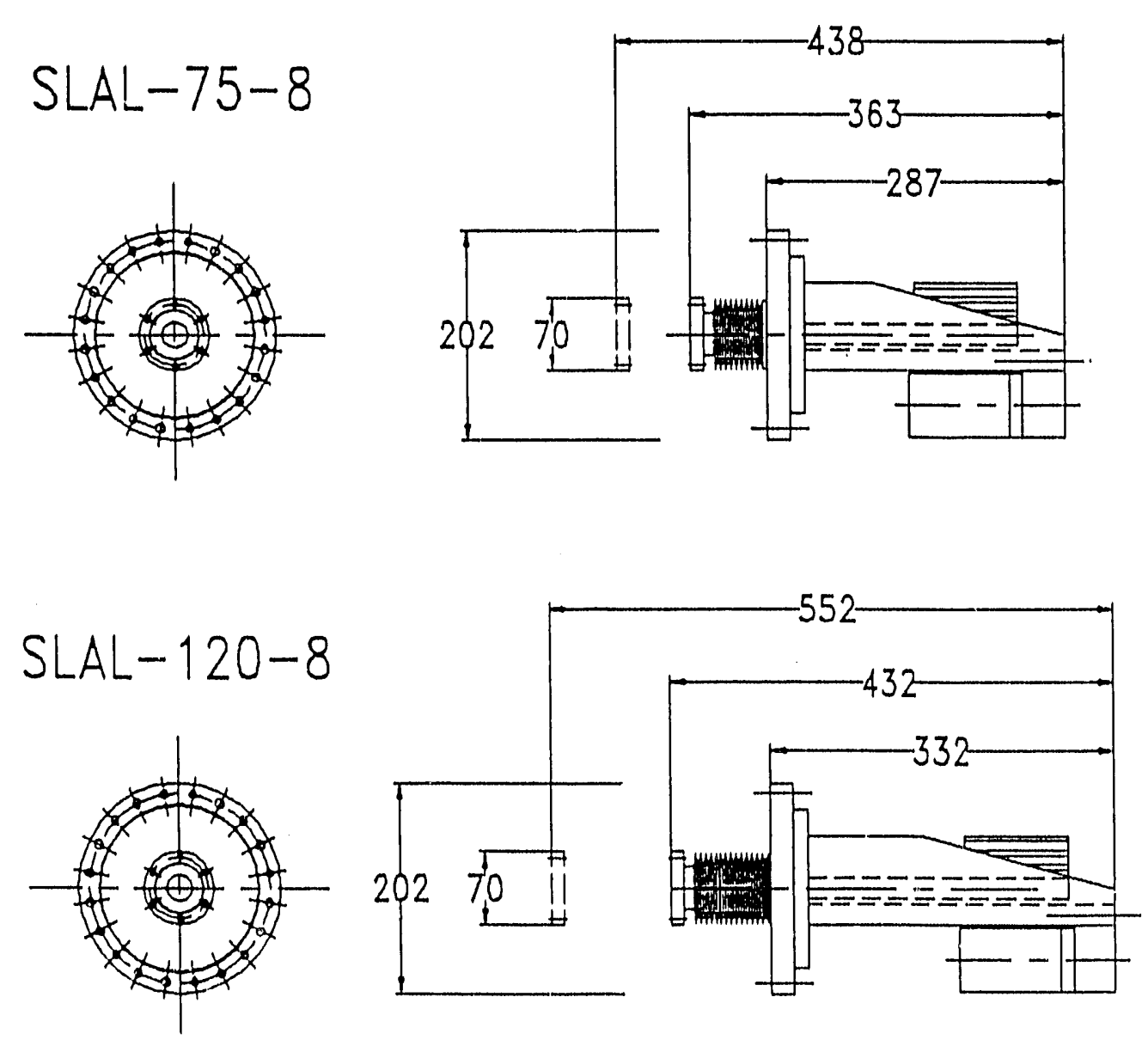

SLAL.DWG 01-18-92

Figure 7-1 


\section{APS Heavy Load Stepping Linear Actuators}

SLAH-30-8, SLAH-75-8, SLAH-120-8

- Heavy load actuators

- For use with APS ID white beam slits

- Stepping motor driven with shaft encoder

A typical application for these actuators is to drive APS ID white beam slits. There are three different ranges of travel designed.

Specifications:

- Slide type:

- Travel ranges:

- Motion resolution:

- Motion reproducibility:

- Straightness:

- Total axial load:

- Vacuum load:

- Minimum useful axial load:

- Stepping motor:

- Actuator flange O. D.:

- Feedthrough flange O. D.:

- Maximum feedthrough diameter:

- Redundant limit switches

-Encoder:

-Maximum speed:

-Vacuum:
Linear rolling

30,75 , and $120 \mathrm{~mm}$

$<5 \mu \mathrm{m}$

$20 \mu \mathrm{m}$

$2 \times 10^{-4} \mathrm{rad} / 25 \mathrm{~mm}$.

$200 \mathrm{~kg}$

$38 \mathrm{~kg}$

$100 \mathrm{~kg}$

Slo-Syn M063-LE06-E

8 inch

4.5 inch

$50 \mathrm{~mm}$

Optical on motor shaft

$20 \mathrm{~mm} / \mathrm{min}$

UHV compatible 


\section{ADVANCED PHOTON SOURCE}

DRAFT APS HEAVY LOAD STEPPING LINEAR ACTUATOR

SLAH-30-8

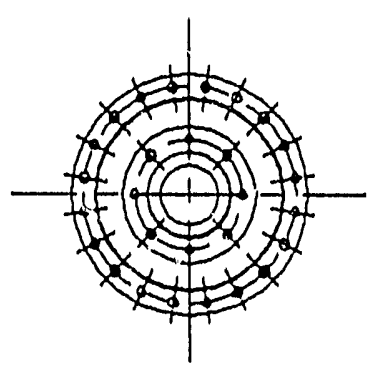

SLAH $-75-8$

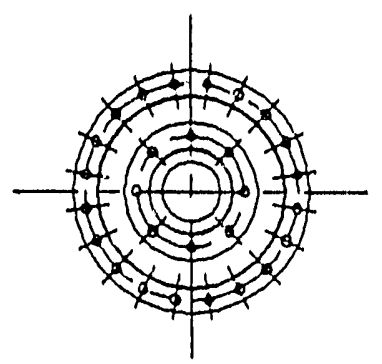

SLAH-120-8

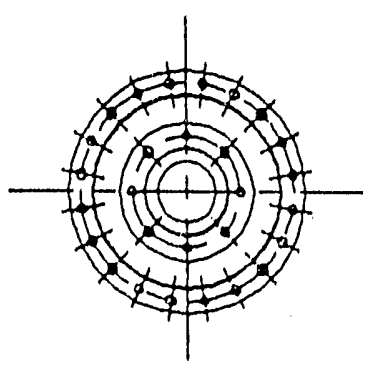

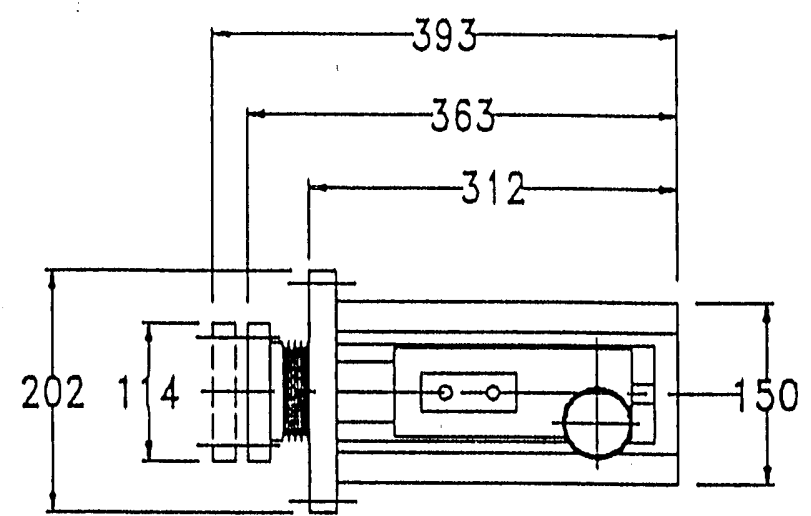

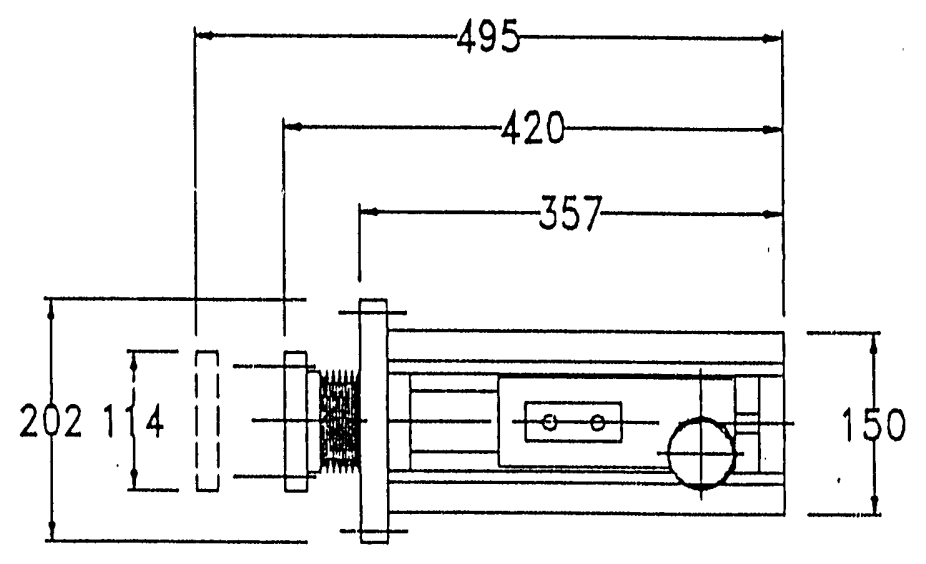

SLAH.DWG $\quad$ U1-18-92

Figure 8-1 


\section{APS Light Load Pneumatic Linear Actuators}

PLAL-52-6, PLAL-52-8

- Light load actuator

- For use with APS monochromatic beam shutters and BM white beam shutters

A typical application for the light load pneumatic actuators is to drive APS monochromatic beam shutters and BM white beam shutters.

Specifications:

- Stroke:

$52 \mathrm{~mm}$

- Motion repeatability:

$0.5 \mathrm{~mm}$

- Total axial load:

$90 \mathrm{~kg}$

- Vacuum load:

$19 \mathrm{~kg}$

- Minimum useful axial load:

$30 \mathrm{~kg}$

- Actuator flange O. D.:

6 and 8 inch

- Feedthrough flange:

2.75 inch

- Maximum feedthrough üiameter:

$25 \mathrm{~mm}$

- Redundant limit switches in each end position

- Pneumatic power supply:

$60-100 \mathrm{psi}$

- Maximum closing time:

$1 \mathrm{sec}$

- Pneumatic damping:

in each end position

- Solenoid:

24 V DC (power failure safe design)

- Life time:

$500 \mathrm{k}$ cycles

-Vacuum:

UHV compatible 


\section{ADVANCED PHOTON SOURCE \\ DRAFT}

\section{APS LIGHT LOAD PNEUMATIC LINEAR ACTUATOR}

PLAL-52-8

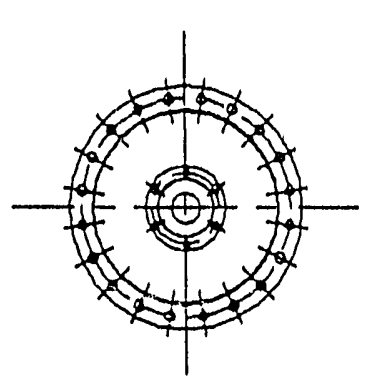

PLAL-52-6

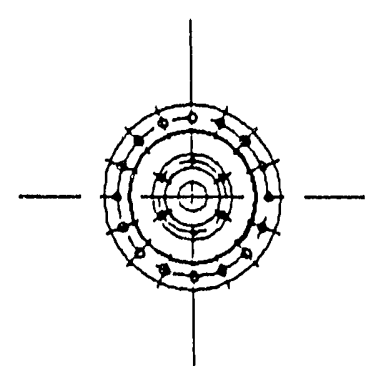

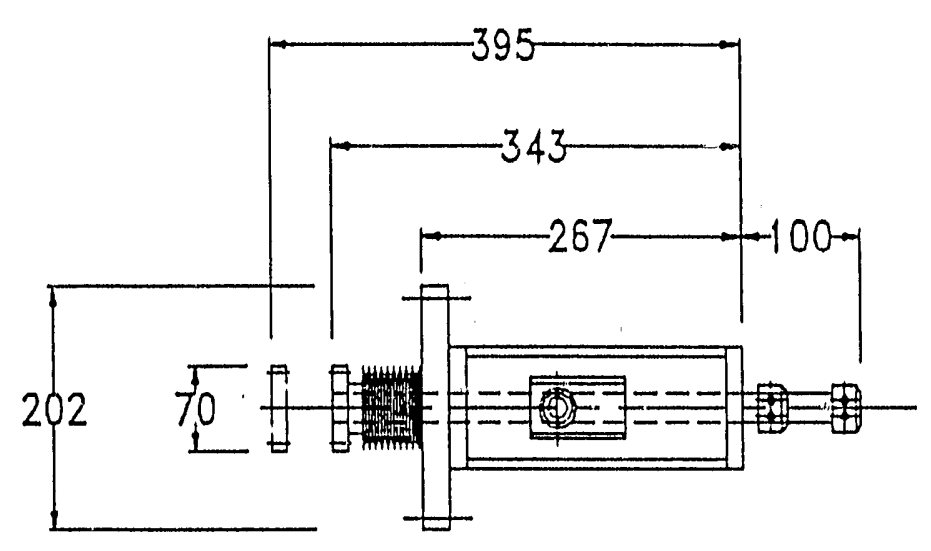

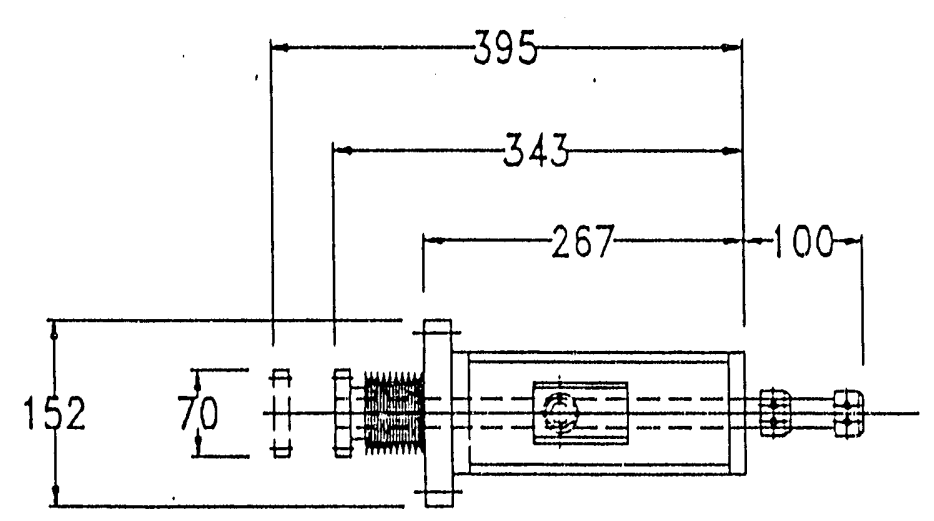

PLAL..DWG 01-18-92

Figure 9-1 


\section{APS Heavy Load Pneumatic Linear Actuators}

PLAH-86-10

- Heavy load actuators

- For use with APS ID and BM front end and beamline safety shutters

A typical application for the heavy load pneumatic actuators is to drive APS safety shutters.

Specifications:

- Stroke:

$86 \mathrm{~mm}$

- Motion repeatability:

$0.5 \mathrm{~mm}$

- Total axial load:

$180 \mathrm{~kg}$

- Vacuum load:

$38 \mathrm{~kg}$

- Minimum useful axial load:

$120 \mathrm{~kg}$

- Actuator flange O. D.:

10 inch

- Feedthrough flange:

4.5 inch

- Maximum feedthrough diameter: $50 \mathrm{~mm}$

- Redundant limit switches in each end position

$\therefore$ Pneumatic power supply:

$60-100 \mathrm{psi}$

- Maximum closing time:

1- $2 \mathrm{sec}$

- Pneumatic damping:

in each end position

- Solenoid:

$24 \mathrm{~V} \mathrm{DC}$ (power failure safe design)

- Life time: $500 \mathrm{k}$ cycles

-Vacuum:

UHV compatible 


\section{ADVANCED PHOTON SOURCE DRAFT}

APS HEAVY LOAD PNEUMATIC LINEAR ACTUATOR
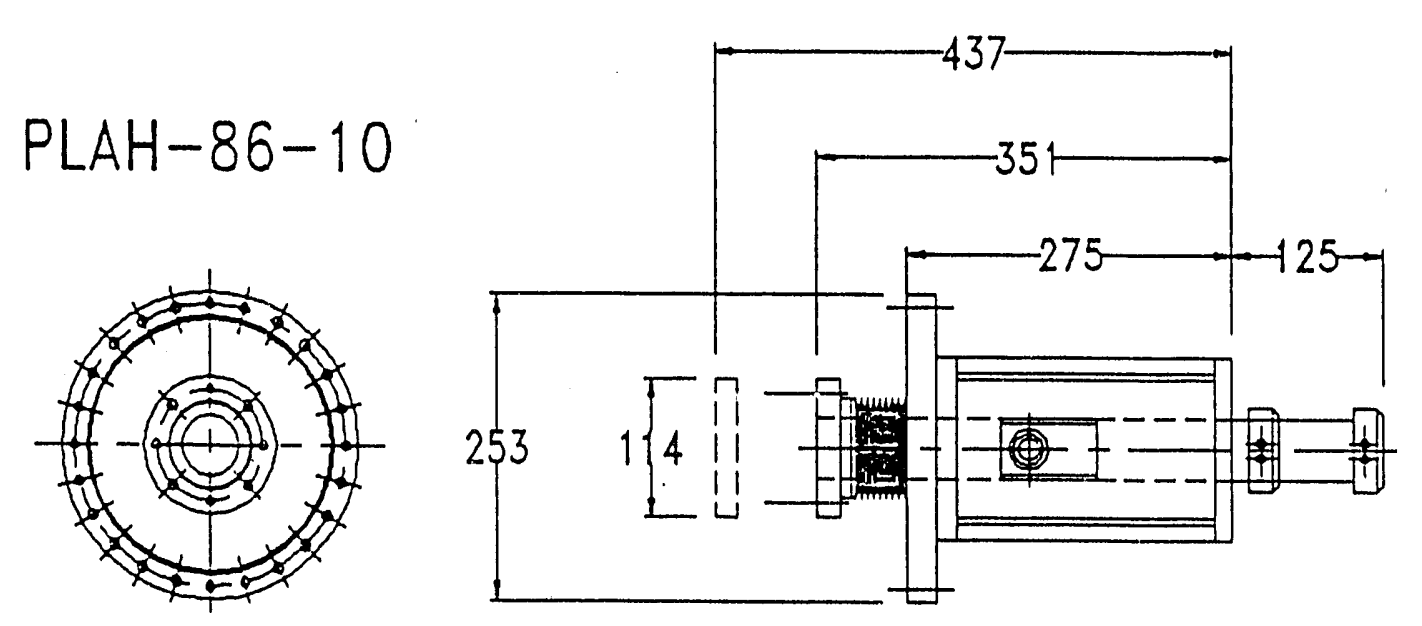

PLAH.DWG 01-18-92

Figure 10-1 


\section{APS Beam Transport Vacuum Specifications}

- Beamiline transport will be evacuated

Bcamlines will be maintained at $<10^{-6}$ Torr. Ion pumps are recommended on the basis of vibration, exhaust, noise, heat, and oil-free operation

Specifications:

- Beamline transport maximum pressure:

10-6 Torr .

- Ion pump interface:

Either RS232 or IEEE488, to be determined

- Flanges:

Conflat

- Roughing port and instrumentation flange:

2.75 inch 


\section{APS Kinematic Mount Support Tables and Kinematic Mount Stages}

- 3-point kinematic support tables

- Tables will have five degrees of freedom: vertical translation, horizontal translation transverse to the beam, and 3 rotations

- Tables can be operated manually or can be stepping motor driven

APS kinematic mount support tables provide for a three-point mounting to align beamline components. The support girders provide for a rigid base with vibration isolation. The travel of the kinematic mount stages is limited by the bellows.

Specifications:

- Minimum supported mass:

$1000 \mathrm{~kg}$

- x-y-x slides:

linear rolling

- Slide maximum:

$450 \mathrm{~kg} /$ slide

- Slide travel range:

$+/-6.35 \mathrm{~mm}$

- Slide motion resolution:

$10 \mu \mathrm{m}$

- Slide motion repeatability:

$50 \mu \mathrm{m}$

- Siide straightness of trajectory:

horizontal: $1 \times 10^{-4} \mathrm{rad} / 25 \mathrm{~mm}$ verticai: $2 \times 10^{-4} \mathrm{rad} / 25 \mathrm{~mm}$ 


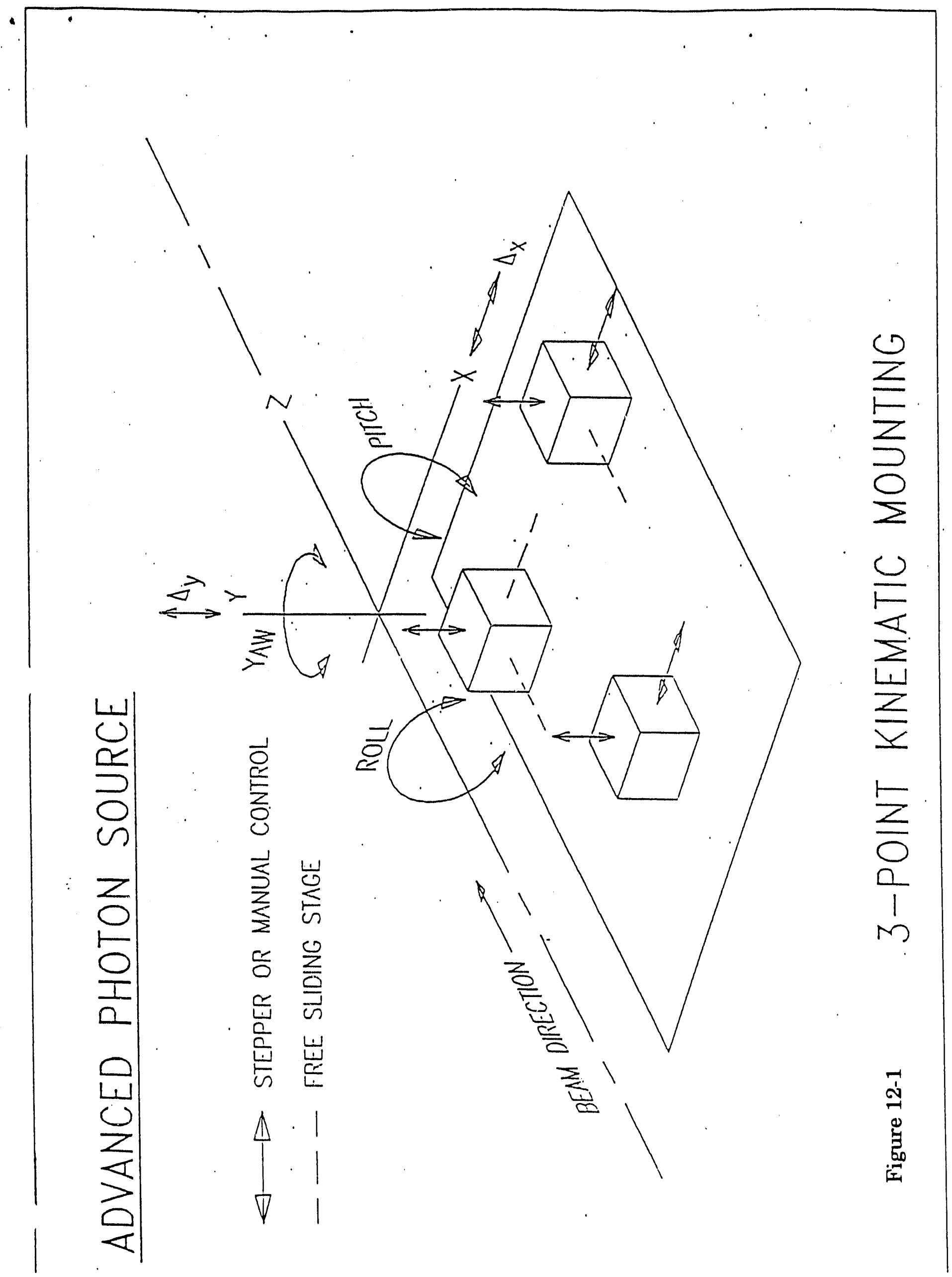




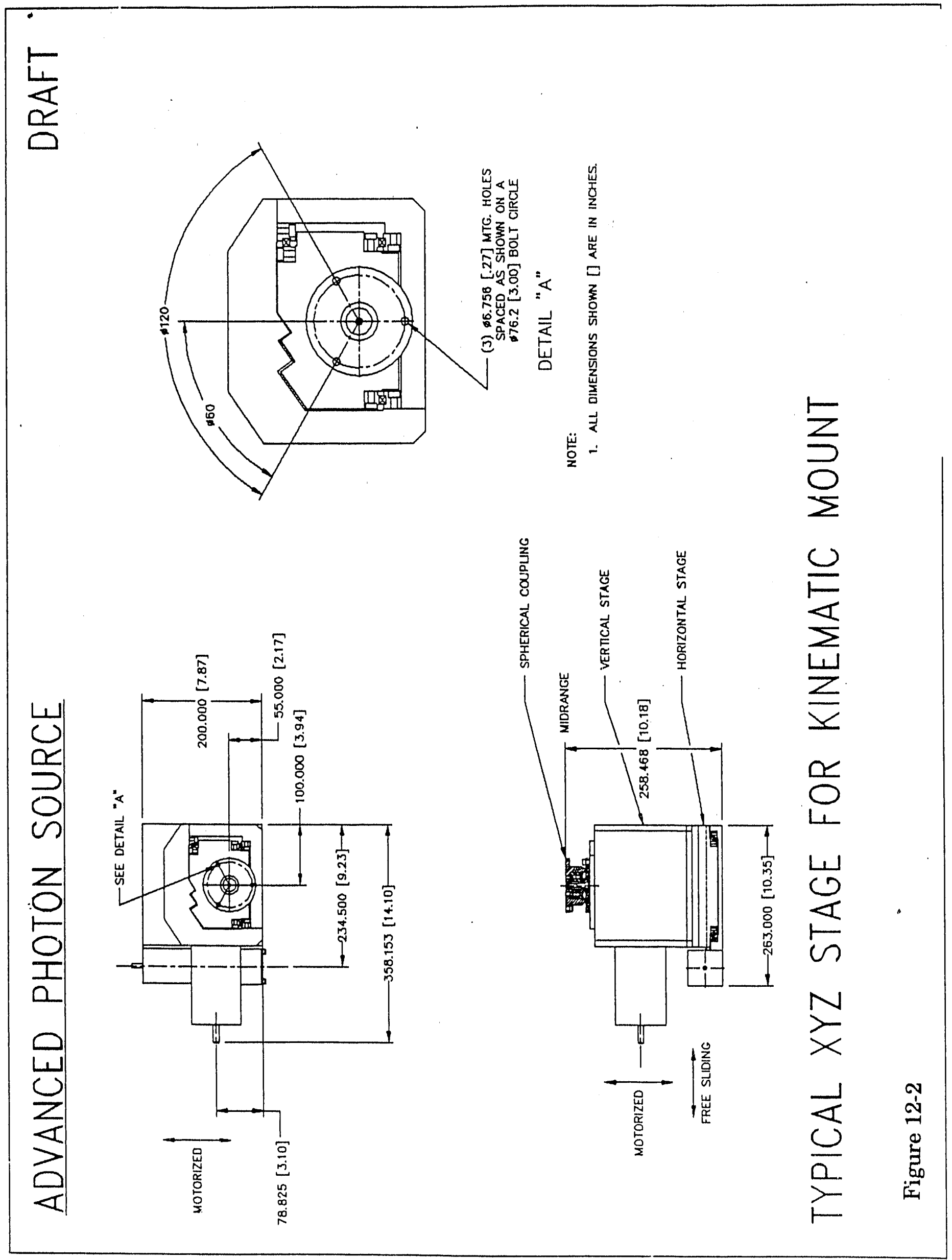




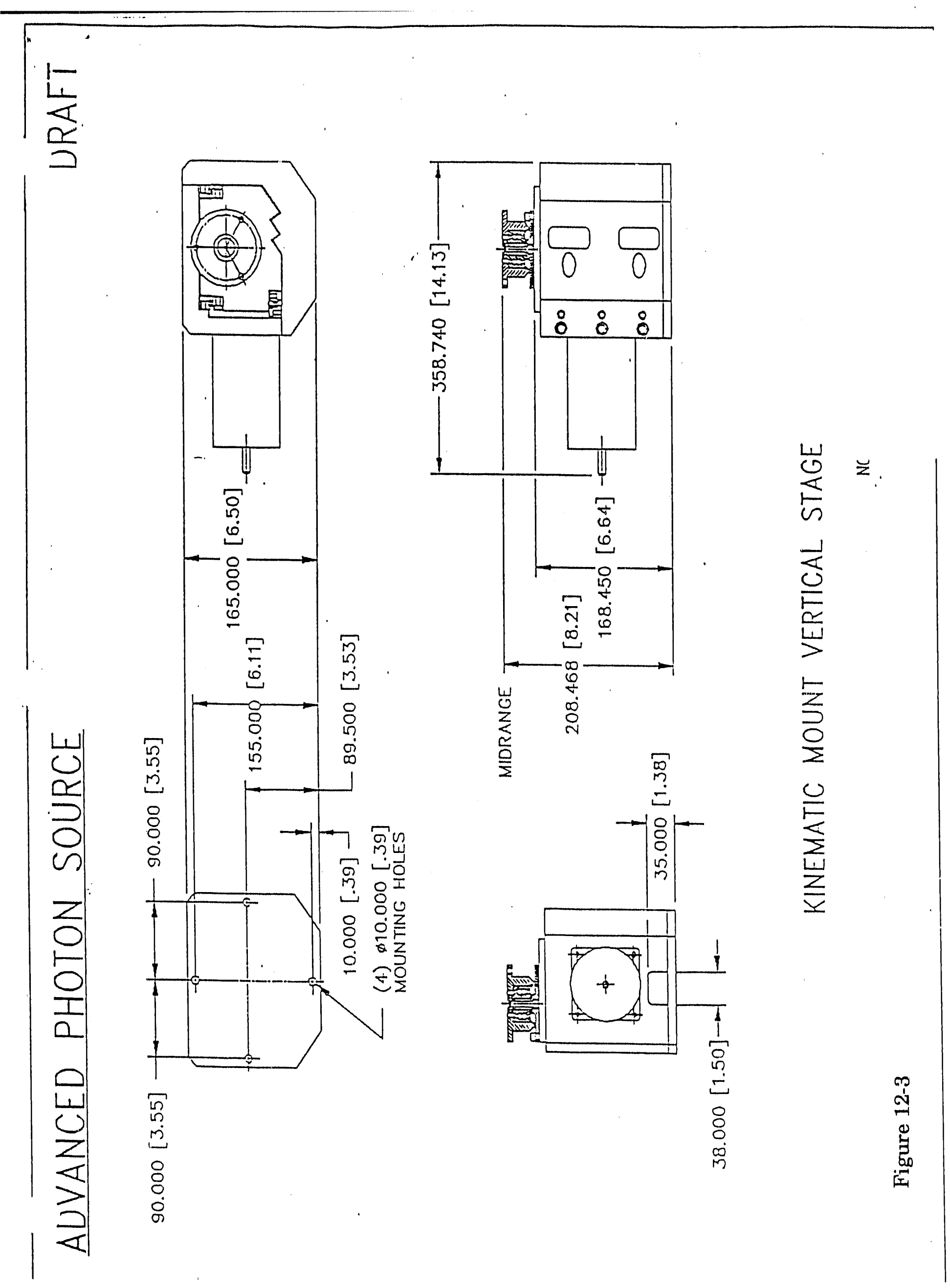




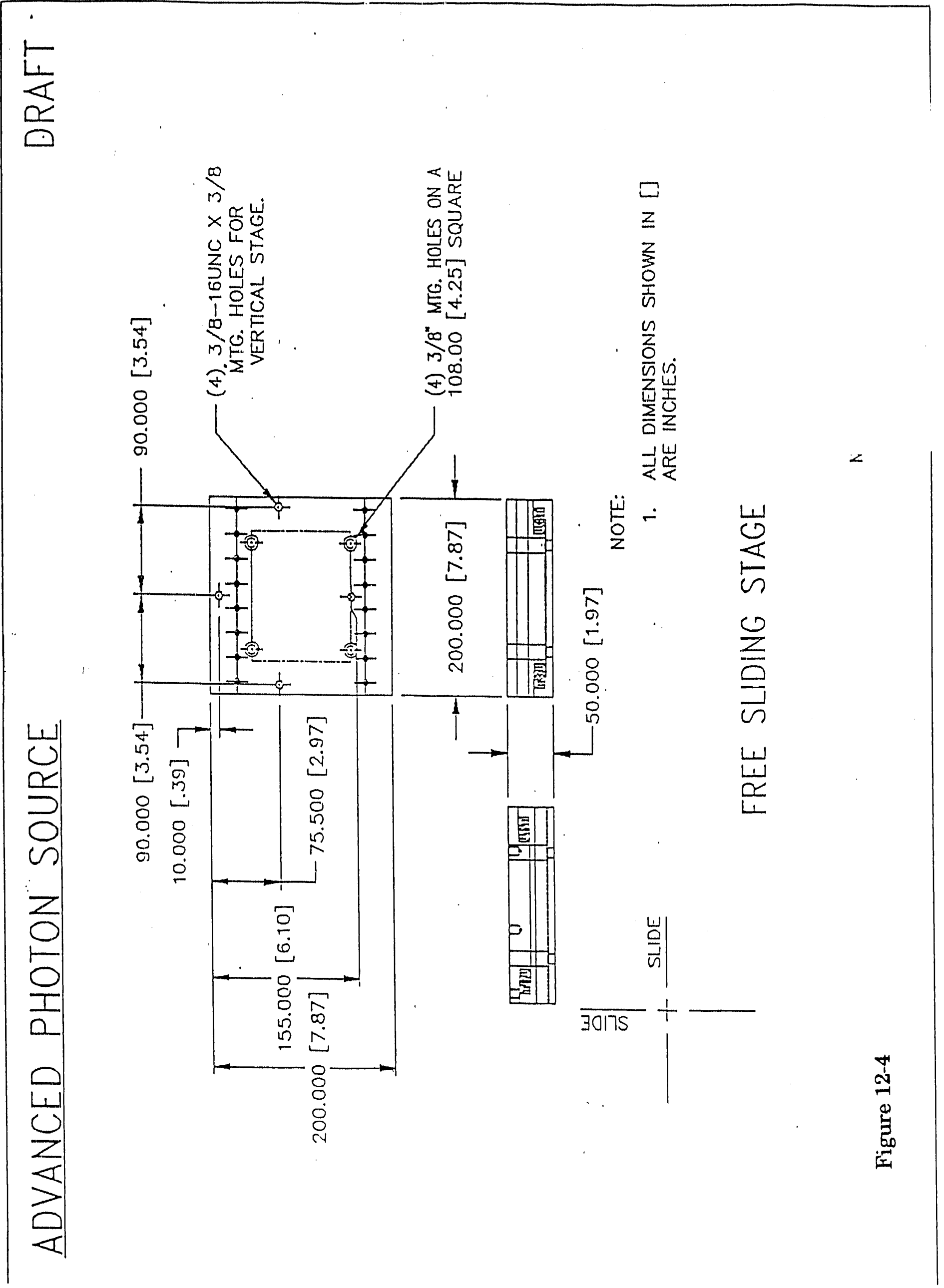




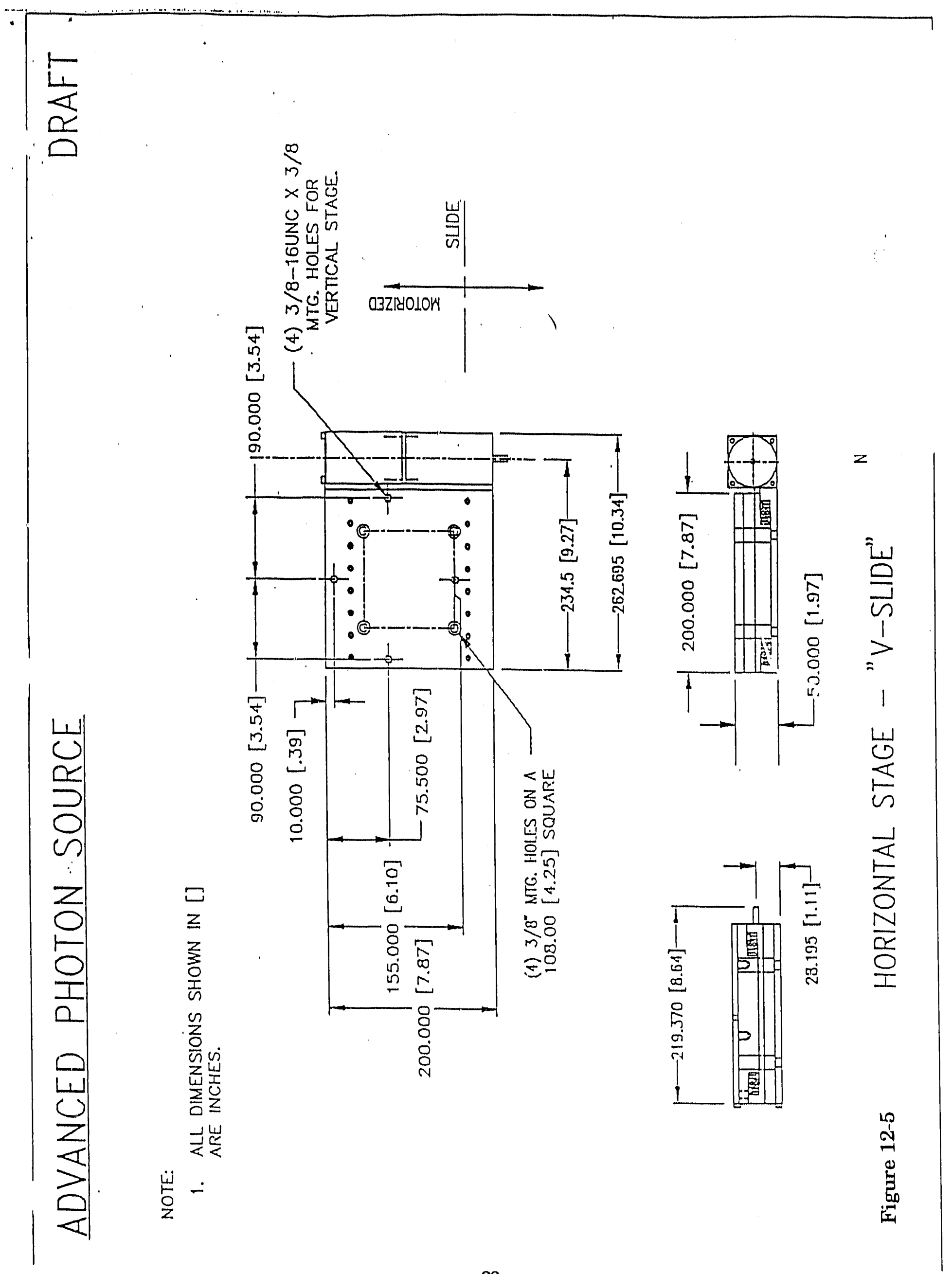




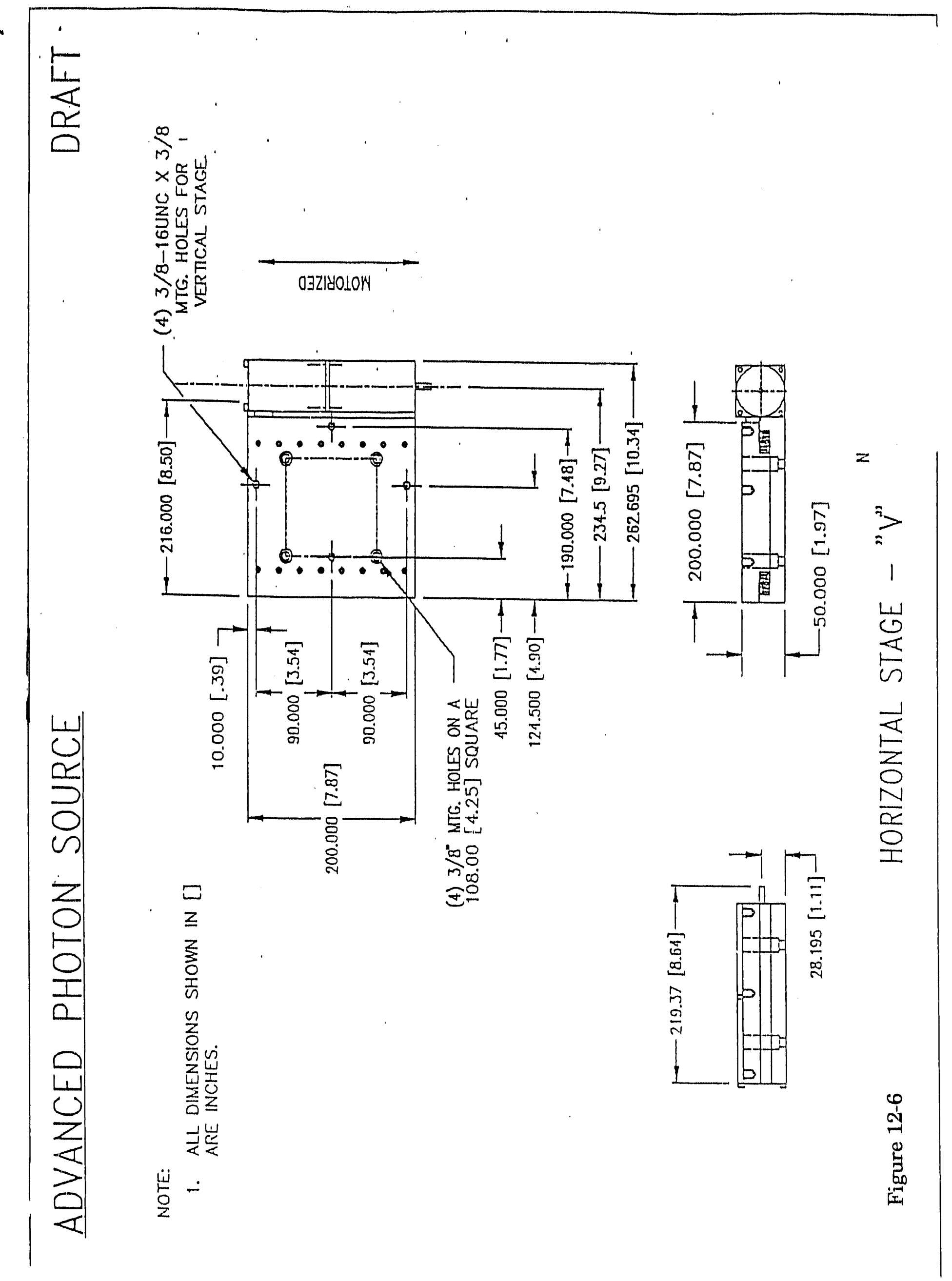




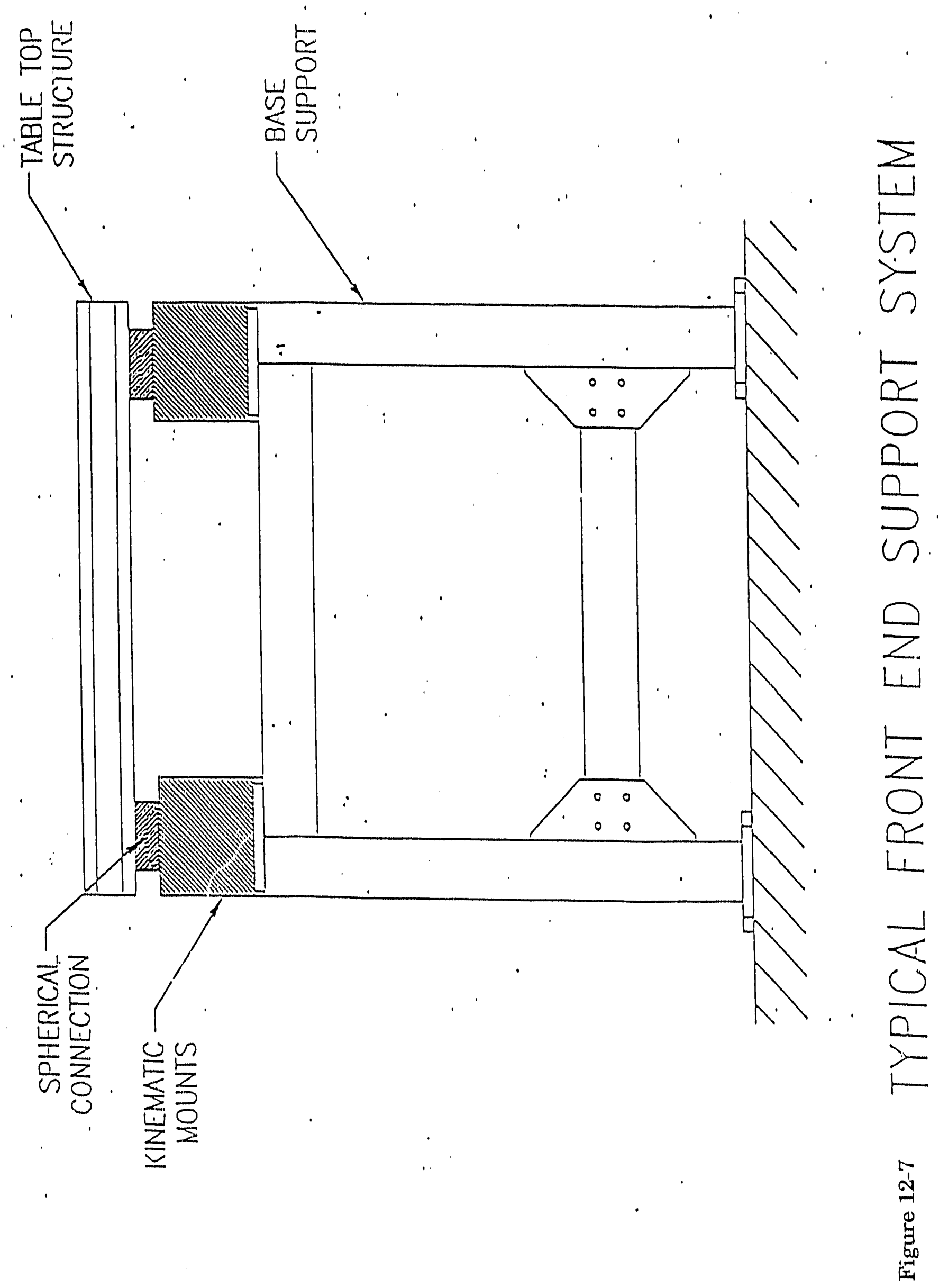




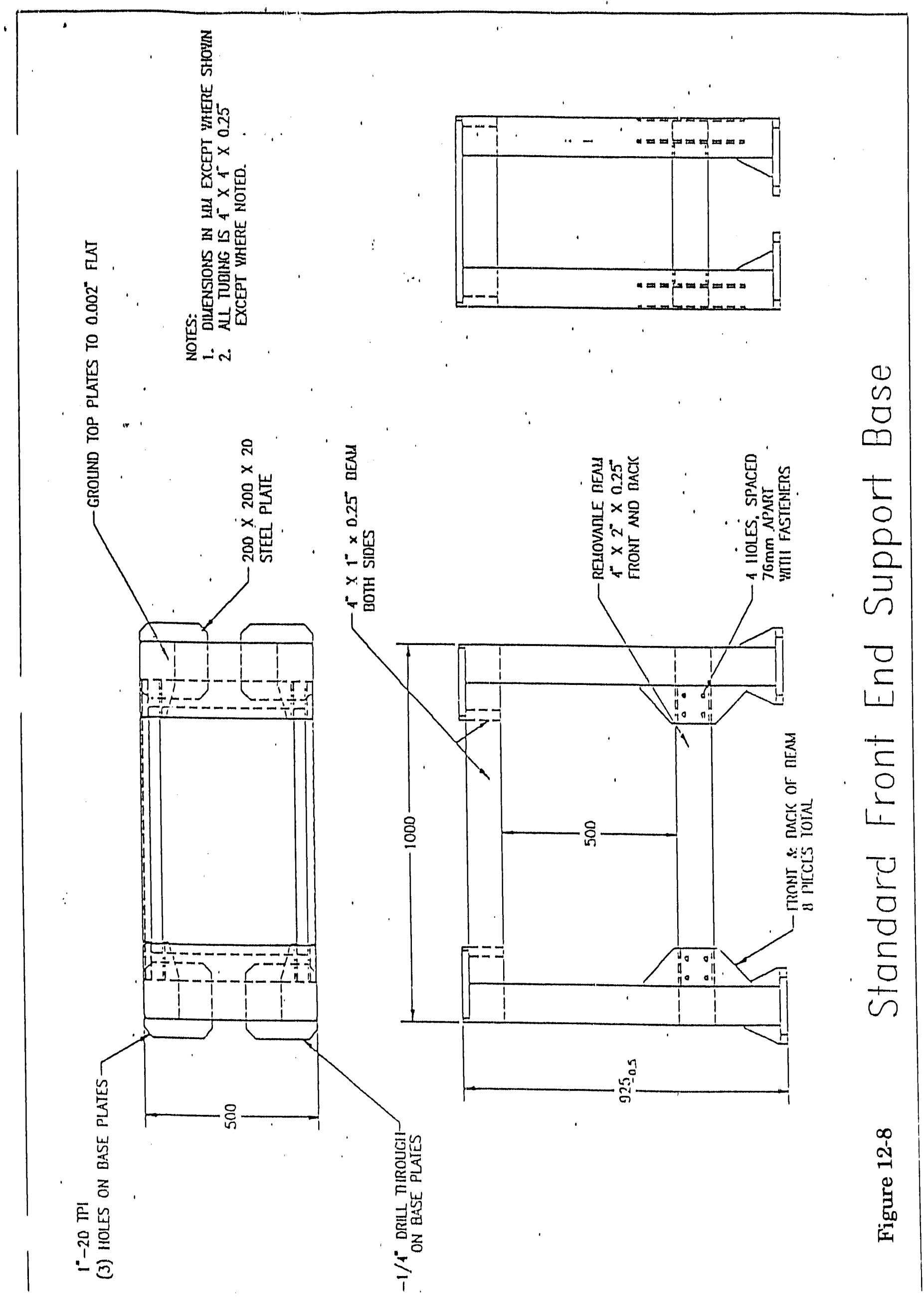




\section{APS FOE and Experimental Station Hutt hes}

- Hutches are lead lined

- Access doors are interlocked for personal safety

- Hutches are of a modular design

Hutches are modular in construction to provide flexibility to the users and to accommodate future changes in beamline design. The hutch access door is operated with a push button either inside or outside the hutch. The door will be automatic and operate smoothly. For personal safety, the doors can be manually opened from the inside in case of a power failure. First optics enclosures (FOE) and white beam hutches rest against the storage ring tunnel wall. Monochromatic beam hutches are stand-alone structures.

Specifications:

- Shielding material: lead and steel

- Shielding thickness: Isee APS Transport and Hutch Shielding Specifications)

- Shielding construction: lead core between two steel plates

- Access door: safety interlocked

- Hutch height: $\quad 10.5$ feet

- Hutch modular panels: $1 \mathrm{~m} \times 3 \mathrm{~m}$ 


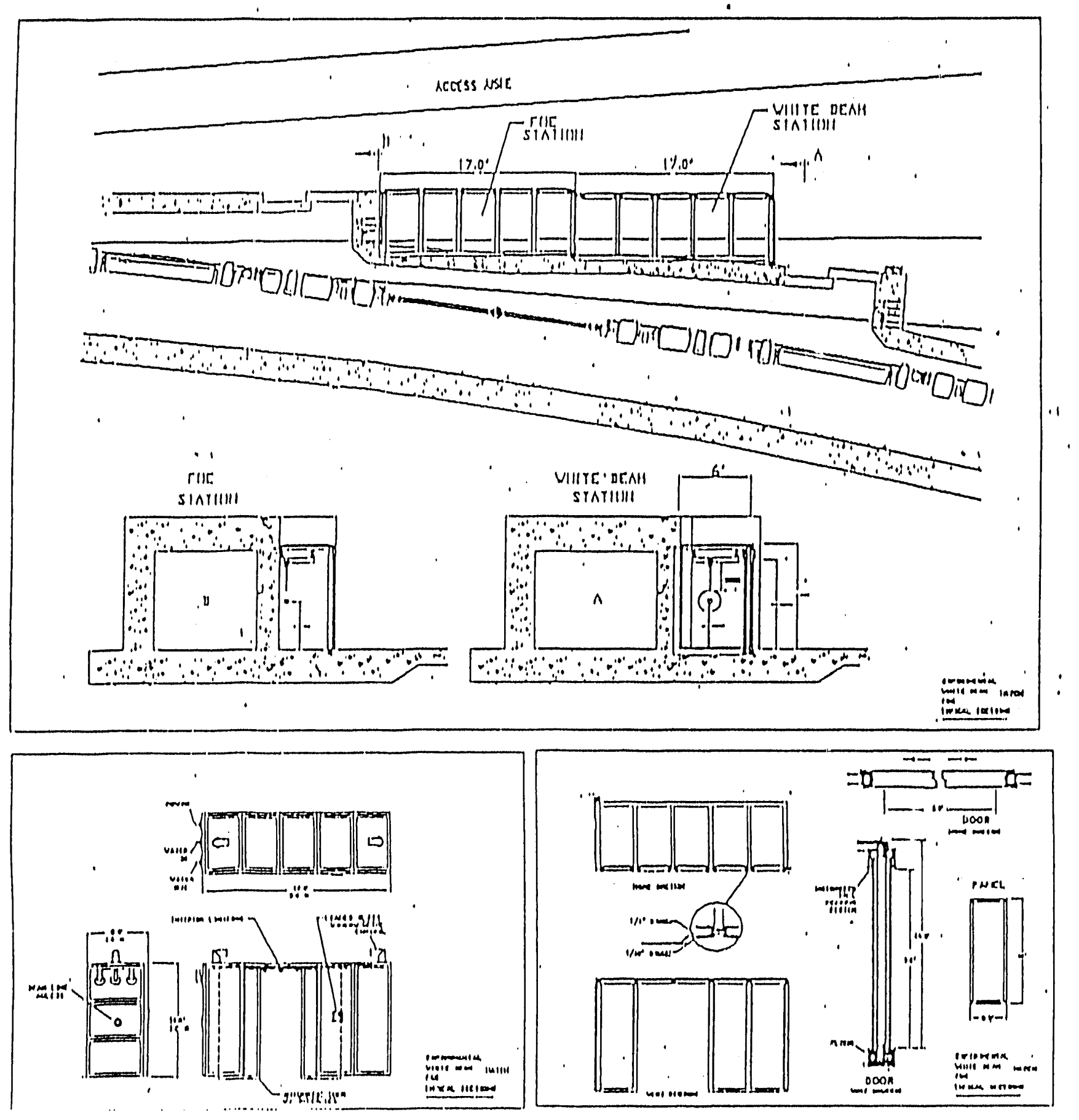

Figure 13-1 First Optics Enclosure 

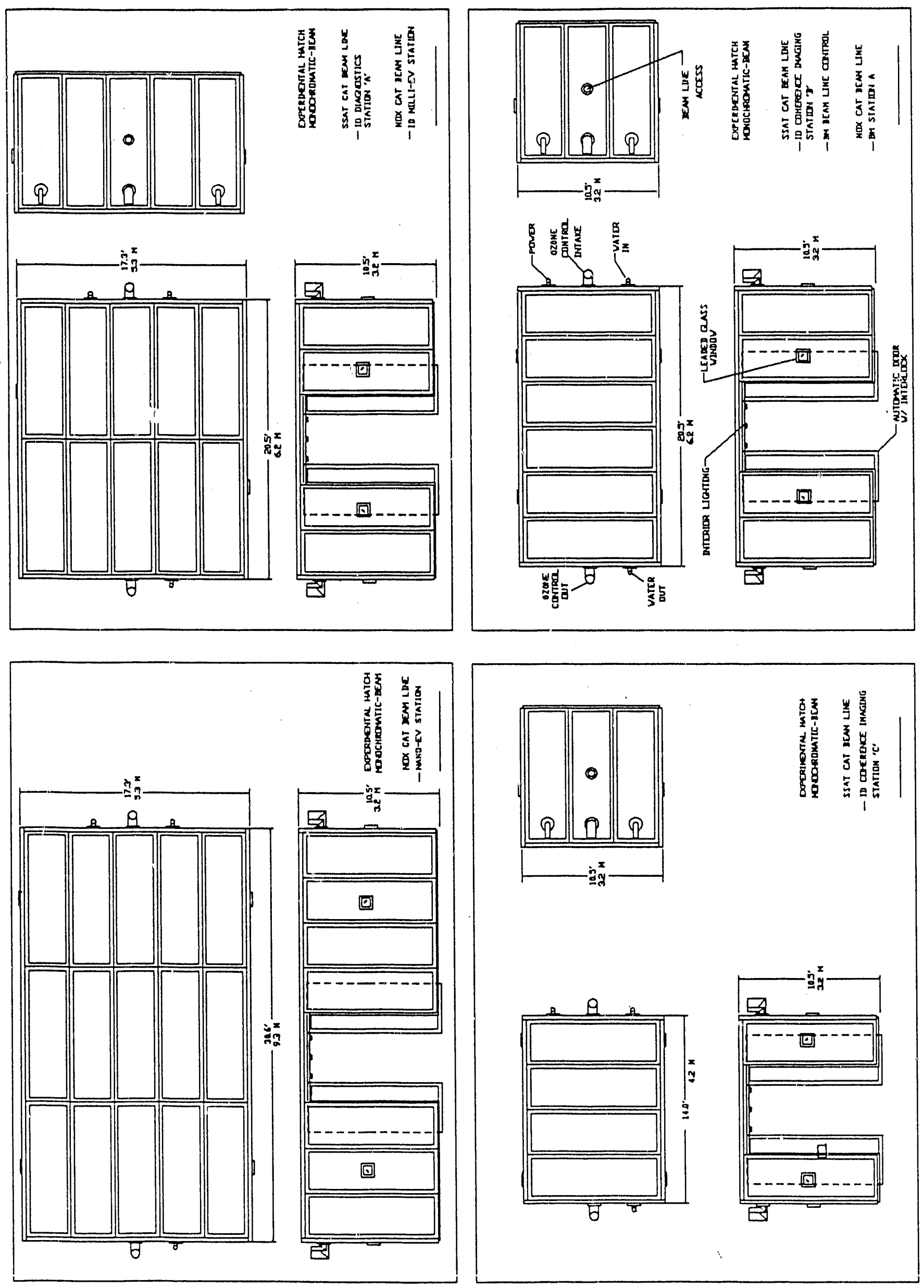


\section{APS Shielded Monochromatic Transport and Pump Station}

- Lead-shielded transport for monochromatic beams

- Lead sandwiched between concentric stainless steel pipes

- Standardized pump station

The APS shielded monochromatic beam transport provides a standard module for beam delivery on the experiment floor. The lead shielding is encased between two stainless steel pipes. A standard section contains a pair of 2-m shielded spool pieces and a $1 \mathrm{~m}$ long pump station. The standard pump station includes a gate valve, ion pump, and bellows.

Specifications:

- Standard length:

$5 \mathrm{~m}(2-2 \mathrm{~m}$ tubes plus $1 \mathrm{~m}$ pump station $)$

Pump station length:

$1 \mathrm{~m}$

- Ion pump speed:

$60 \mathrm{l} / \mathrm{sec}$

- Gate valve seal:

Viton 

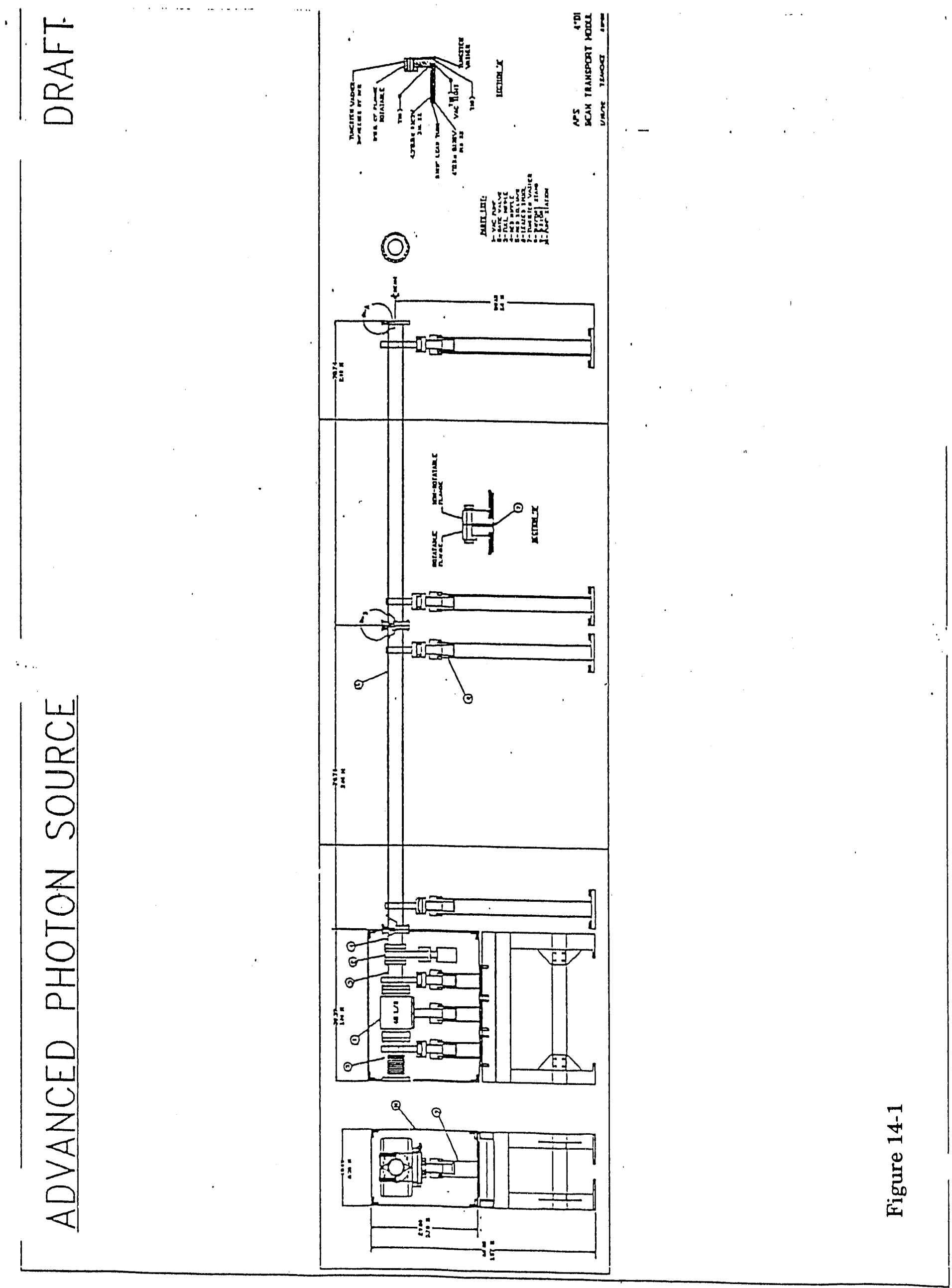
$\mid \frac{W}{\sigma}$

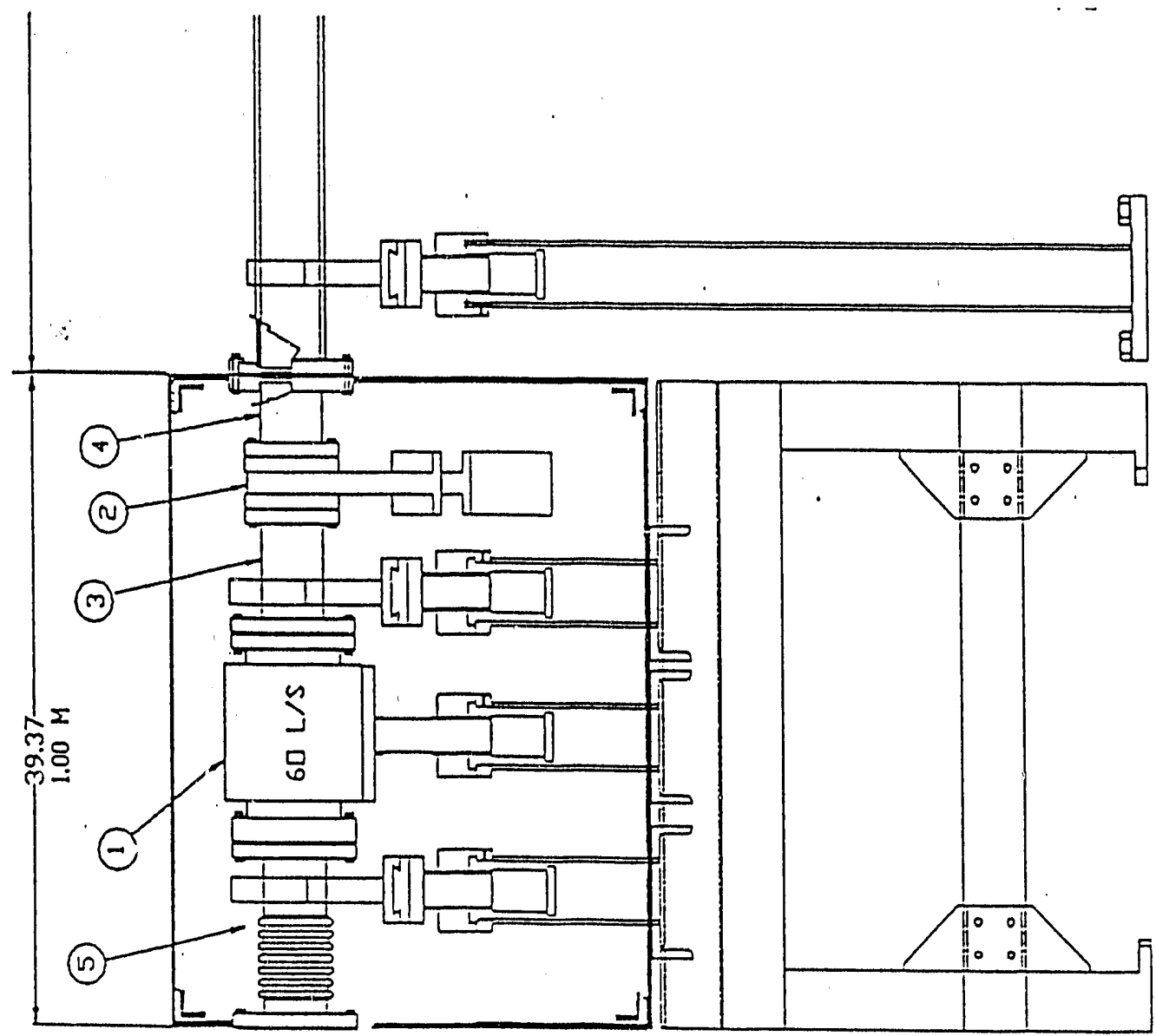

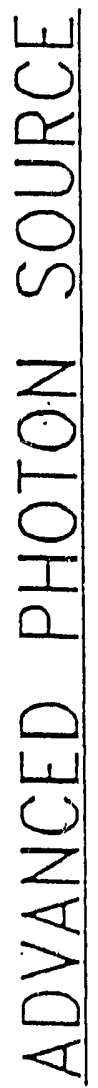

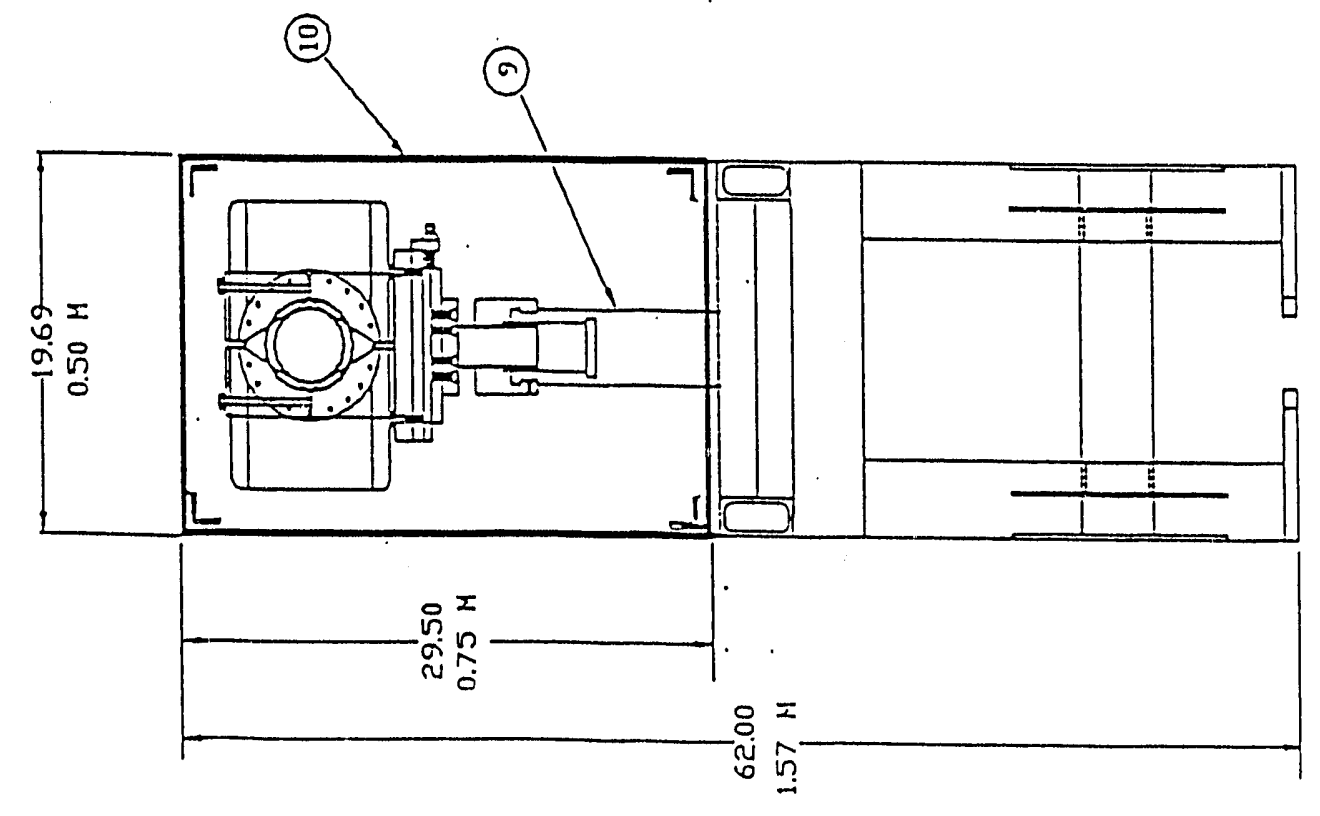

告 


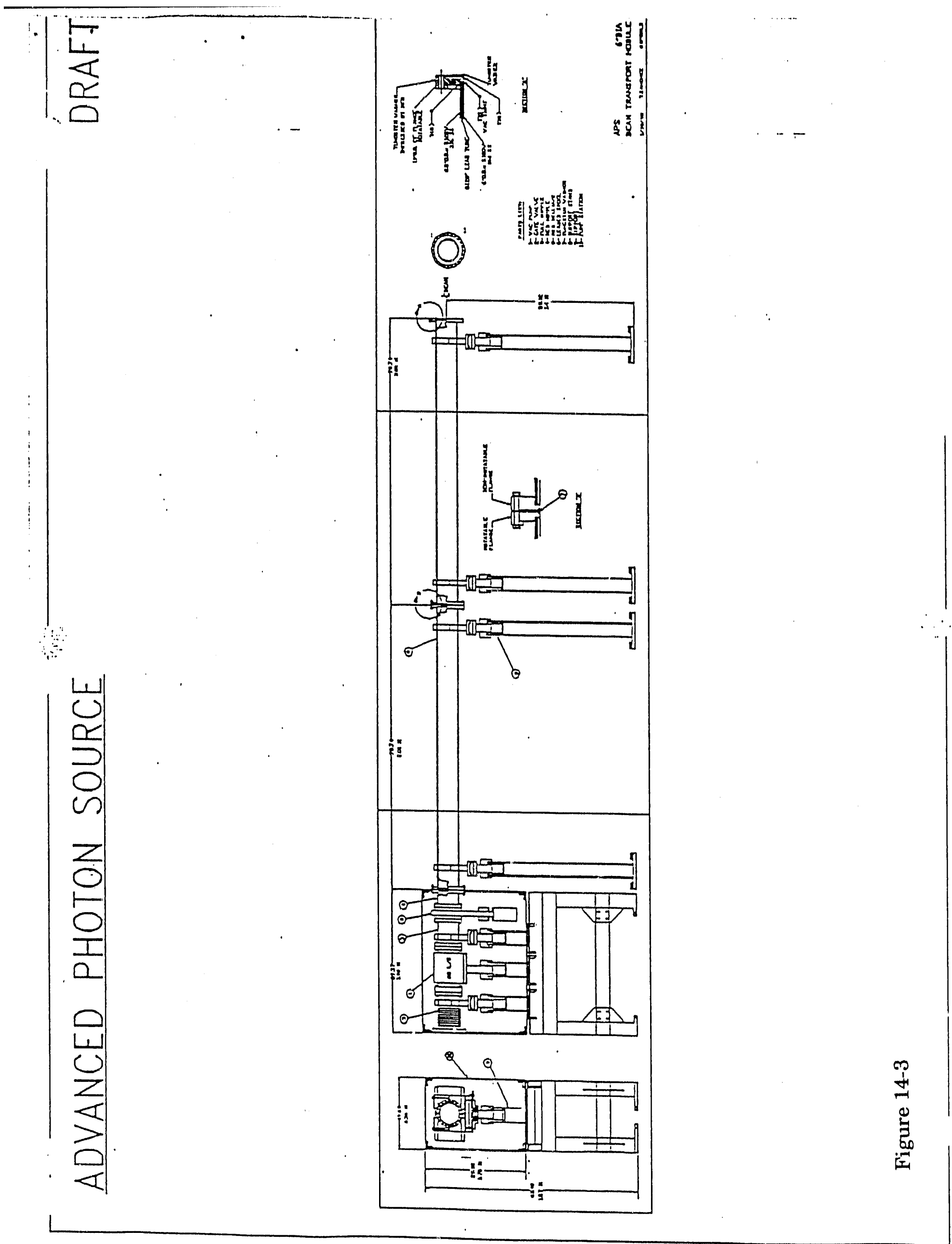


龄
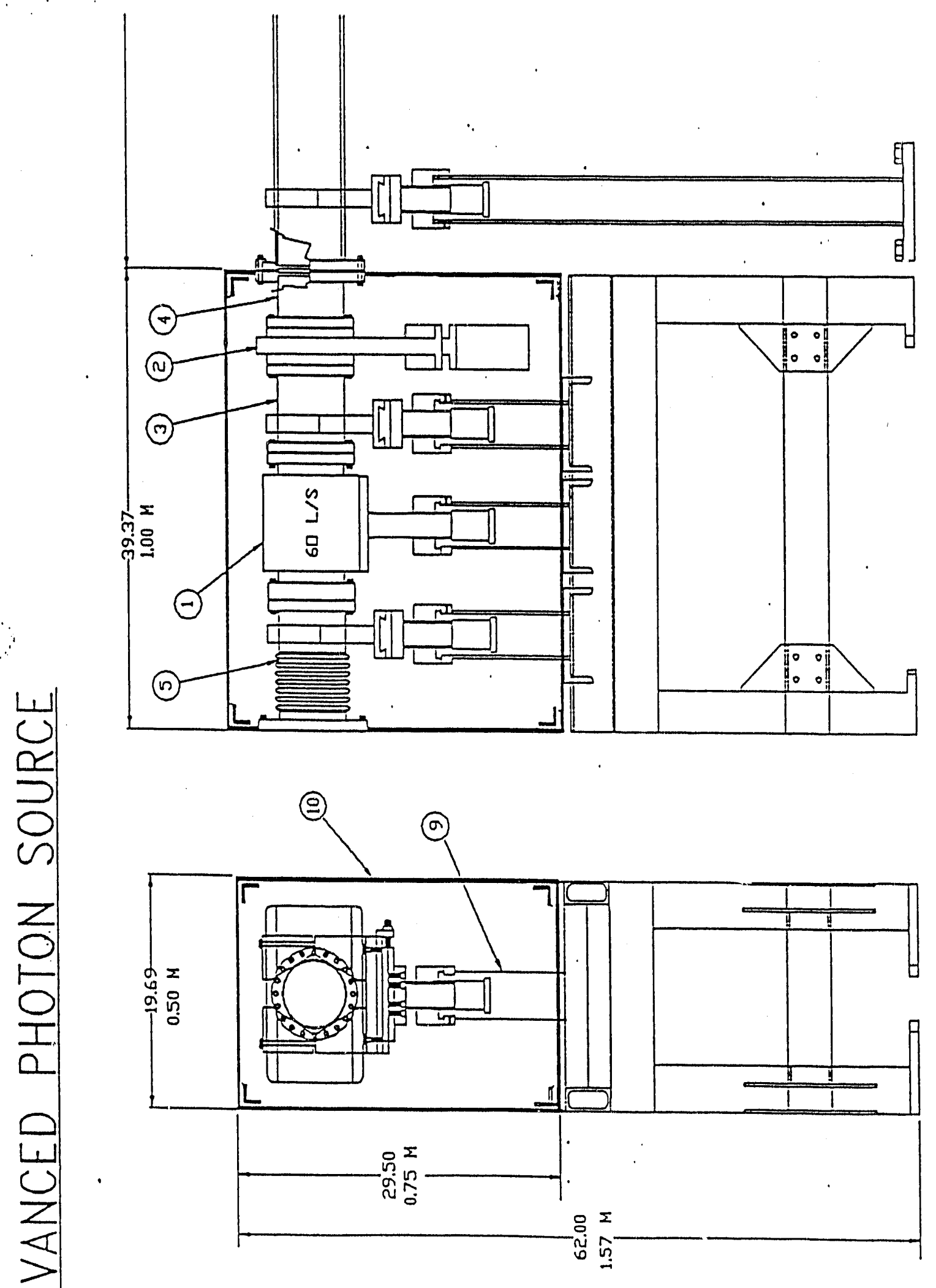
$\mid \frac{5}{\frac{\pi}{\sigma}}$

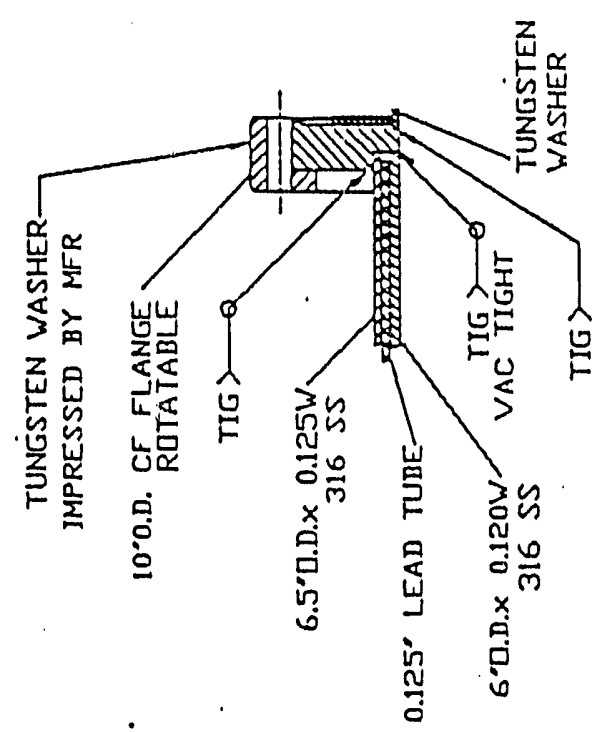

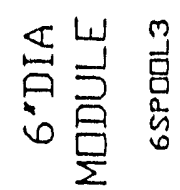

京|

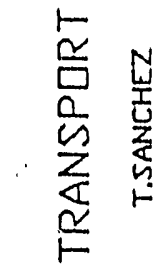

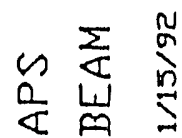

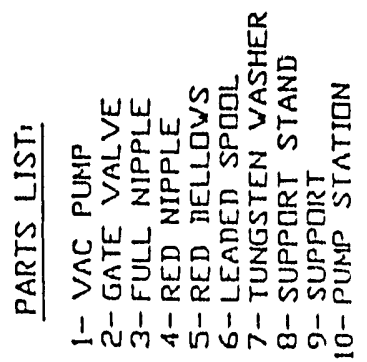

1
0
0
0
0
$z$
0
0
1
0
0
0
$z$
$\square$
$\square$

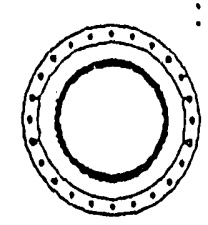

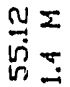

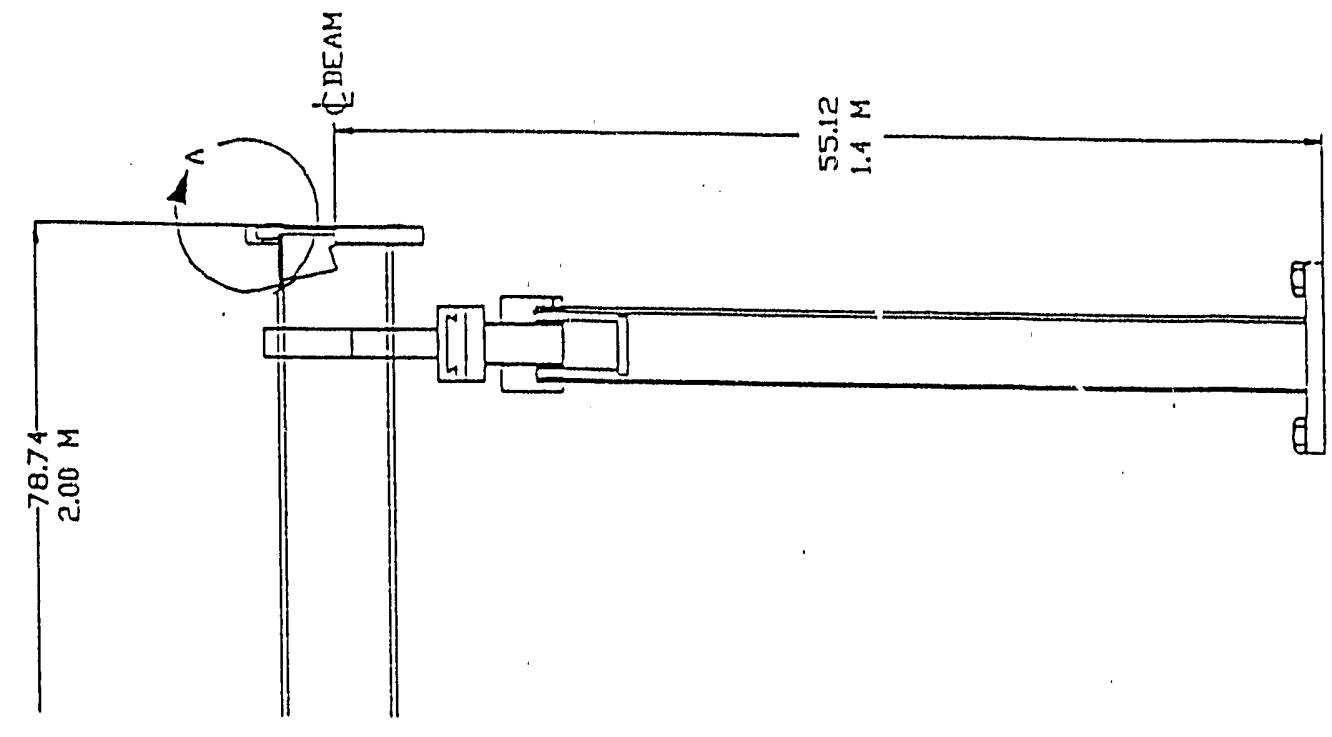

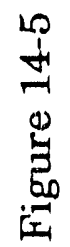




\section{APS Stepping Motor Drivers/Controllers}

- Standardize stepping motor drives and controllers

- Control for multi-motor driven systems

- Open and/or closed loop control

- Acceleration and deceleration control

- Power fail-safe control with battery backup coordinate memory

The APS stepping motor driver/controller is designed to provide a user friendly control environment for multi-motor driven systems such as kinematic mounting tables or beamline slits. Control is to be either manual or through computer control.

Specifications:

- Stepping motor:

four phase, 400 half steps/rev, $3 \%$ accuracy M063-LE06-E: $3.36 \mathrm{~V}$ DC, 2.9 A

M093-FD8107-E: 4.3V, 3.5A

- Maximum stepping rate:

40000 half steps/sec

- Able to interface with computer

- Position display:

seven digit and sign with computer conversion

- Feedback:

open and/or closed loop with TTL incremental encoder signals

- Memory backup:

battery backup nonvolatile memory of control data

- Power fail safe

- Switch status information to host: open or closed of limits or home

- Connectors

(to be standardized)

- Cables

(to be standardized) 


\section{APS Be Windows}

- Standard Be window design

Beamline $\mathrm{Be}$ windows will be designed with vertical apertures approximately consistent with the window's structural strength. The mount will be designed with a small negative rake to prevent reflections from the mounting fixture.

Specifications:

- Material:

Be

- Window thickness:

$10 \mathrm{mil}$

- Vertical aperture:

$20 \mathrm{~mm}$

- Horizontal aperture:

(to be specified for maximum aperture consistent with standard flange diameter)

- Flange size:

6, 8, and 10 in. O.D. 


\section{APS Monochromatic Beam Position Monitors/Supports}

- $\mathrm{BPM}$ resolution $0.1-0.5 \mu \mathrm{m}$

The monochromatic beam position monitor (BPM) will be supported on the same type of stand as the front-end BPMs.

Specifications:

- Minimum range:

$5 \mathrm{~mm}$

- Motion resolution:

$0.5-1.0 \mu \mathrm{m}$

- Response:

$1 \mathrm{kHz}$

- BPM support load capacity:

$90 \mathrm{~kg}$

- BPM support travel range:

$+/-5 \mathrm{~mm}$

- BPM support angular range:

$+/=2 \mathrm{deg}$

- BPM support linear resolution:

$0.2 \mu \mathrm{m}$

- BPM support angular resolution:

0.5 arcseconds

- BPM support repeatability:

horizontal: $+/-5 \mu \mathrm{m}$ vertical: $+/-2 \mu \mathrm{m}$ angular: 5 arcseconds

- BPM support maximum speed:

$10 \mathrm{~mm} / \mathrm{min}$

- BPM support straightness of trajectory:

$1 \times 10^{-5} \mathrm{rad} / 25 \mathrm{~mm}$

- BPM support maximum deviation for $45 \mathrm{~kg}$ load offset: $10^{-5} \mathrm{rad} / 12.5 \mathrm{~mm}$ 


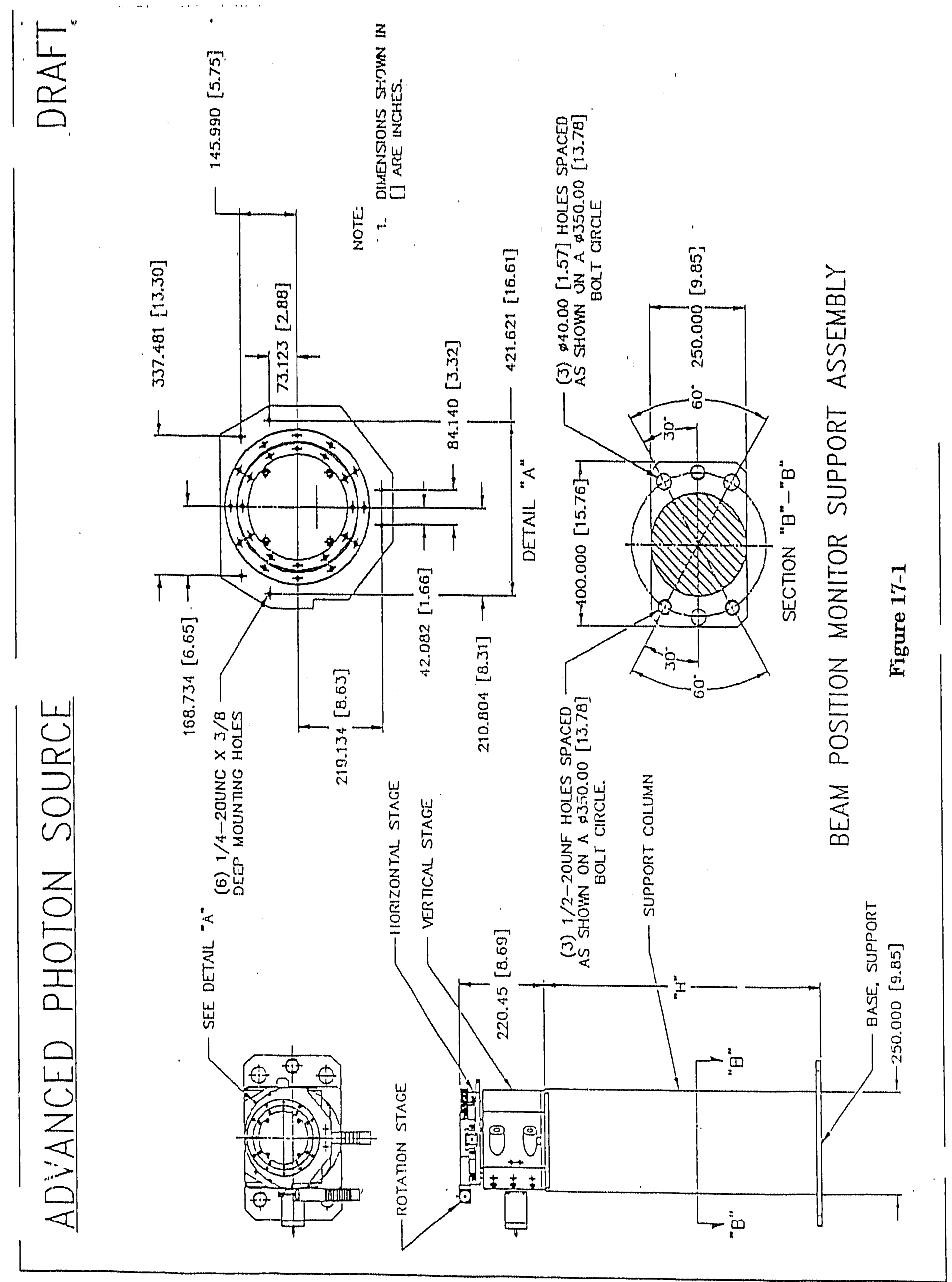




\section{Collimators}

(design not yet included in Handbook, version 1.1) 


\section{APS Transport and Hutch Shielding Specifications}

- Beamline transport and hutches will be shielded to keep occupational doses at acceptable levels

The current Argonne-acceptable occupational dose is $3.0 \mathrm{rem} /$ year and is likely to be reduced to $1.5 \mathrm{rem} /$ year. Current shielding designs are to keep doses to $<1$ rem/year. The shielding will be designed considering meaningful "worst case scenarios." Shielding will be specified for white and monochromatic beams, for ID and magnet beamlines, and for beam transport and hutches (refer to APS FOE and the Experimental Station Hutches).

Specifications:

- Lead shielding:

(see Table 19-1, next page) 


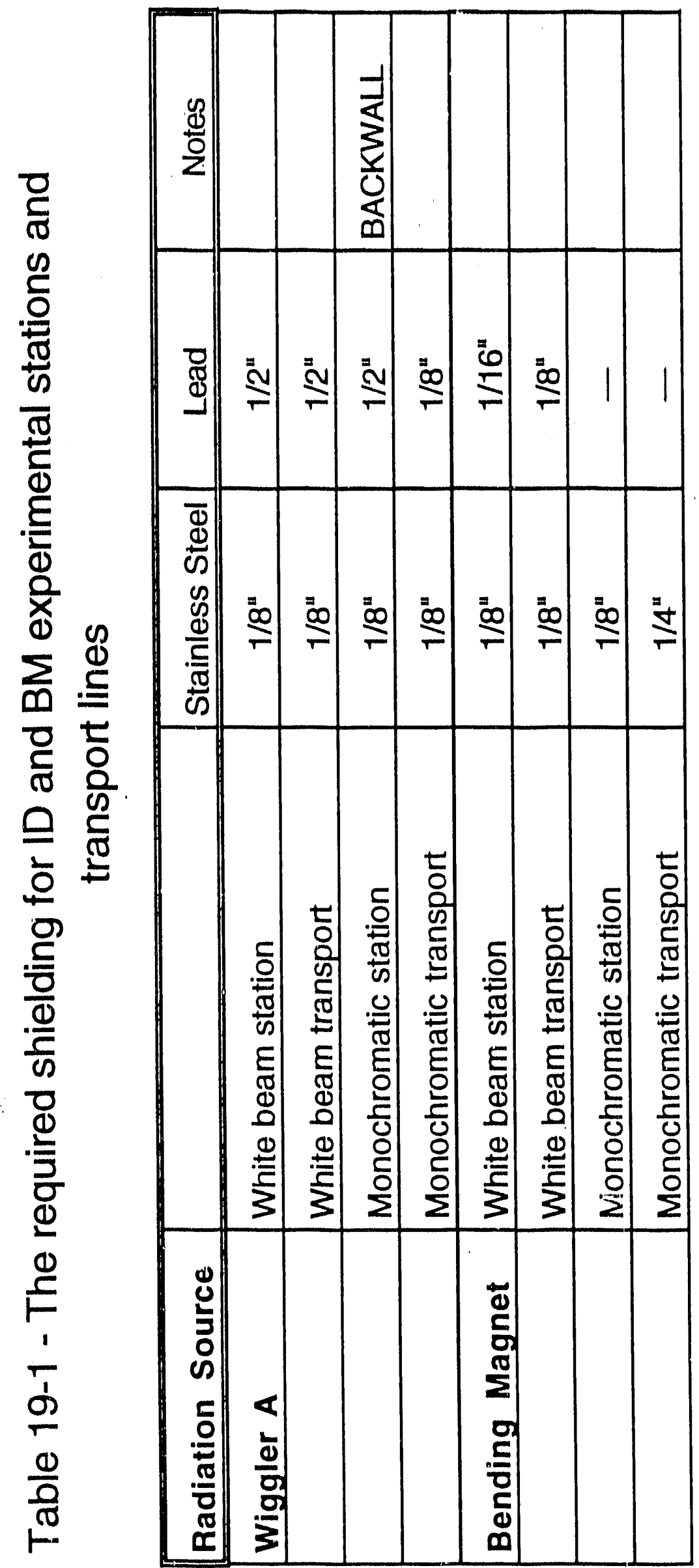




\section{APPENDIX A}

\section{Beamline Standardization and Modularization Charge Gopal Shenoy, Jan. 22, 1990}

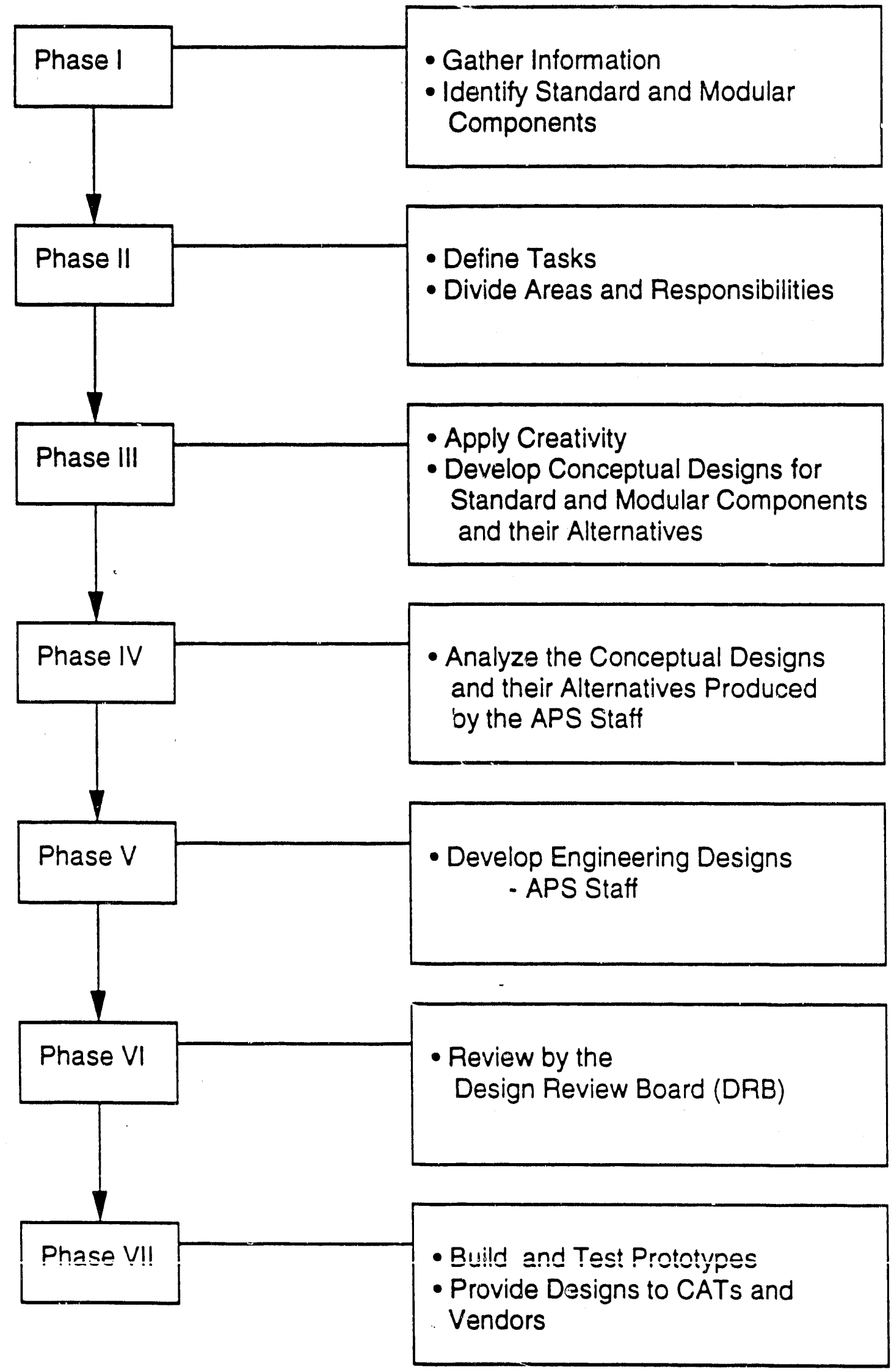



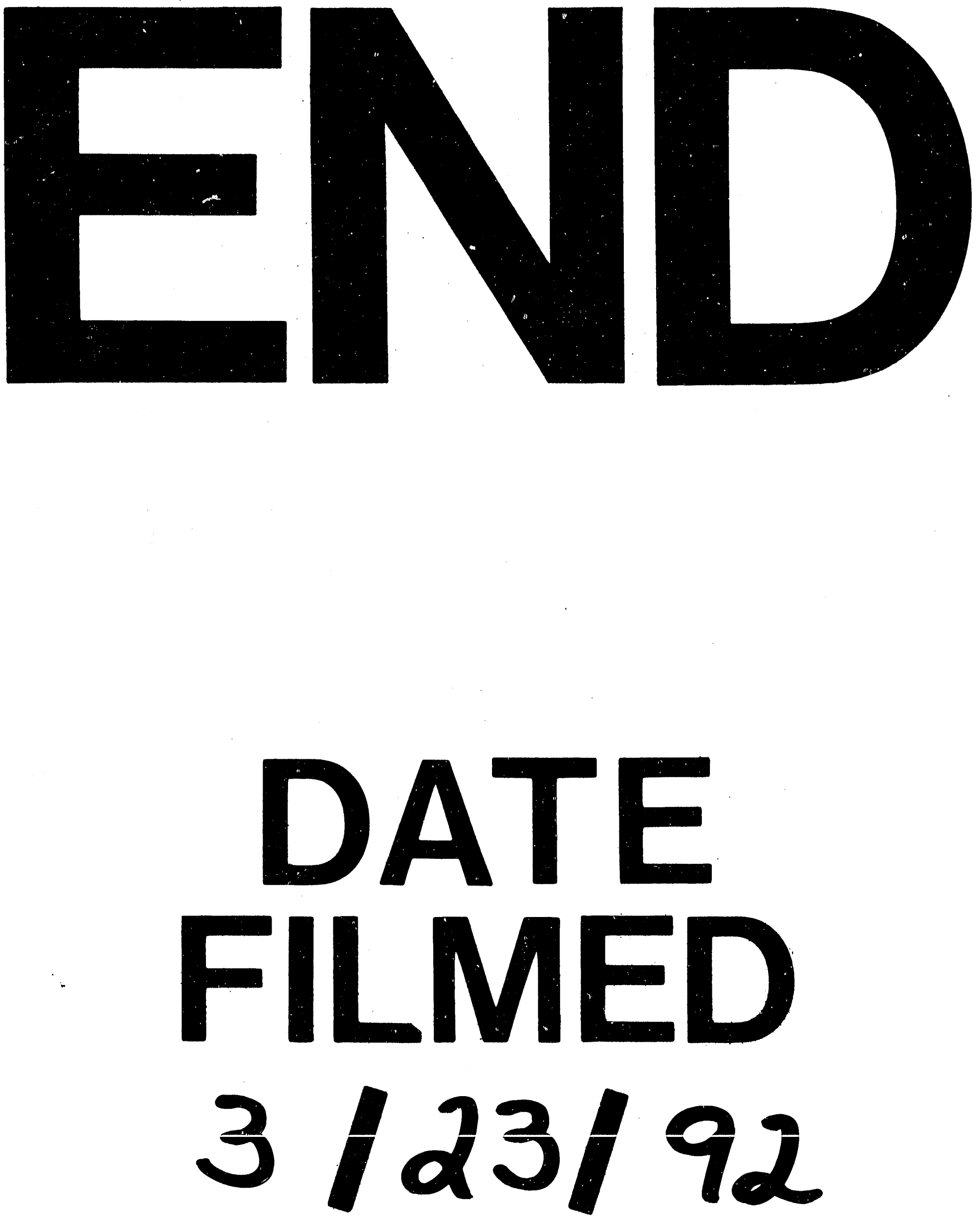

1 
